\title{
Effect of radar rainfall time resolution on the predictive capability of a distributed hydrologic model
}

\author{
A. Atencia ${ }^{1,2, *}$, L. Mediero ${ }^{3}$, M. C. Llasat ${ }^{2}$, and L. Garrote ${ }^{3}$ \\ ${ }^{1}$ Meteorological Service of Catalonia, Barcelona, Spain \\ ${ }^{2}$ Department of Astronomy and Meteorology, Faculty of Physics, University of Barcelona, Barcelona, Spain \\ ${ }^{3}$ Department of Hydraulic and Energy Engineering, Technical University of Madrid, Madrid, Spain \\ *now at: Department of Atmospheric and Oceanic Sciences, McGill University, Montreal, Canada
}

Received: 23 September 2010 - Published in Hydrol. Earth Syst. Sci. Discuss.: 13 October 2010

Revised: 31 October 2011 - Accepted: 6 November 2011 - Published: 21 December 2011

\begin{abstract}
The performance of a hydrologic model depends on the rainfall input data, both spatially and temporally. As the spatial distribution of rainfall exerts a great influence on both runoff volumes and peak flows, the use of a distributed hydrologic model can improve the results in the case of convective rainfall in a basin where the storm area is smaller than the basin area. The aim of this study was to perform a sensitivity analysis of the rainfall time resolution on the results of a distributed hydrologic model in a flash-flood prone basin. Within such a catchment, floods are produced by heavy rainfall events with a large convective component. A second objective of the current paper is the proposal of a methodology that improves the radar rainfall estimation at a higher spatial and temporal resolution. Composite radar data from a network of three $\mathrm{C}$-band radars with 6-min temporal and $2 \times 2 \mathrm{~km}^{2}$ spatial resolution were used to feed the RIBS distributed hydrological model. A modification of the Window Probability Matching Method (gaugeadjustment method) was applied to four cases of heavy rainfall to improve the observed rainfall sub-estimation by computing new $\mathrm{Z} / \mathrm{R}$ relationships for both convective and stratiform reflectivities. An advection correction technique based on the cross-correlation between two consecutive images was introduced to obtain several time resolutions from $1 \mathrm{~min}$ to 30 min. The RIBS hydrologic model was calibrated using a probabilistic approach based on a multiobjective methodology for each time resolution. A sensitivity analysis of rainfall time resolution was conducted to find the resolution that best represents the hydrological basin behaviour.
\end{abstract}

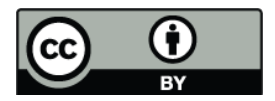

Correspondence to: A. Atencia (atencia@am.ub.es)

\section{Introduction}

Accurate flash flood hydrological modelling requires both a suitable hydrologic model and rainfall data of proper spatial and temporal resolution. The spatial variability of rainfall exerts great influence on basin processes (Winchell et al., 1998). This, especially holds for convective precipitation events, as the storm area is usually smaller than the basin area (Bell and Moore, 2000). The spatial distribution of rainfall can influence runoff volumes, peak flows and the lag time of hydrographs (Krajewski et al., 1991; Arnaud et al., 2002). Therefore, a distributed model can improve the simulation of flash floods events compared to using a lumped model, as the former takes the spatial variability of rainfall into account. Furthermore, a more recent study by Carpenter and Georgakakos (2006) has shown that distributed model simulations are statistically distinguishable from the lumped model simulations for basin areas around $1000 \mathrm{~km}^{2}$.

The success of hydrological models is usually constrained by the rainfall data they use (Berne et al., 2004). Such input data can be obtained from rain gauge networks, and deterministic or even probabilistic meteorological models. These data sources usually present serious disadvantages for midsize and small basins with irregular spatial rainfall distributions. Surface rain gauge networks with the appropriate resolution for accurate hydrological modelling are rare, and it is not so easy to implement a meteorological model with a sufficiently high grid resolution due to data and computational requirements. Meteorological radar can solve this problem thanks to indirect rainfall estimations at higher spatial and temporal resolutions.

However, this indirect estimation presents different sources of errors, from ground clutter or beam overshooting

Published by Copernicus Publications on behalf of the European Geosciences Union. 
(Sánchez-Diezma et al., 2001), to radar calibration or attenuation (Delrieu et al., 2000). These errors can be reduced by removing static radar echoes, periodic maintenance or selecting the highest reflectivity value from each of the radars of which the network is composed. Once these errors have been partially removed and the reflectivity has been interpolated into different levels called the Constant Altitude Plan Position Indicator (CAPPI), the rainfall intensity can be obtained by applying a Z/R relationship to the lowest CAPPI reflectivity value. The literature shows many $\mathrm{Z} / \mathrm{R}$ relations, from the classical Marshall and Palmer (1948) to more recent ones for different climate types, rain regimes and climatic seasons (Lee and Zawadzki, 2005; Sánchez-Diezma et al., 2000; Steiner et al., 1995; Haddad et al., 1997, to name just a few contributions).

The choice of one or another $\mathrm{Z} / \mathrm{R}$ relation could alter the rainfall intensity obtained. Several methods have been developed in recent years over the Mediterranean area to obtain a suitable QPE, although they are strongly dependent on case studies. Apart from Z/R relations, there are other methods for obtaining a suitable rainfall field. Some of the latest methods are related to the direct correction of rainfall maps using multi-linear regression (Morin and Gabella, 2007), merging rain gauge and radar data by means of non-parametric spatial models (Velasco-Forero et al., 2004), studying the Vertical Profile of Reflectivity (Franco et al., 2008), making use of the measured attenuation (Bouilloud et al., 2010) or the use of disdrometer data (Hazenberg et al., 2011). Matching the unconditional probabilities of rainfall intensity obtained from rain gauges and reflectivity (Rosenfeld et al., 1994) is another approach to this problem. This method, which is known as Window Probabilistic Matching Method (WPMM), will be applied in this paper.

Another problem is that the rainfall intensity, especially for the convective type, continuously varies due to flux advection or mountainous enhancement. According to Fabry et al. (1994), sampling errors can be large, but they are easily avoidable given the computing power available today. The current paper corrects for sampling errors using an advection correction scheme based on a cross-correlation technique (Rinehart and Garvey, 1978). In order to avoid this sampling error, an intensity variation between images based on temporal interpolation (Anagnostou and Krajewski, 1999) has been applied in the present study. However, in the current paper this shape morphology transformation is conducted by means of using temporal dependent weights based on a more complex shape transformation (Turk and O'Brien, 2005).

The Real-time Interactive Basin Simulator (RIBS) is a topography-based, rainfall-runoff model that can be used for real-time flood forecasting in mid-size and large basins (Garrote and Bras, 1995a). Once the rainfall is well estimated and a suitable hydrological model is applied, the key factor is the calibration of the hydrological model. Non-linear features of distributed models can amplify the intrinsic rainfall errors (Smith et al., 2004). For this reason, distributed models may be optimised for real-time flood simulations and some physical processes parameterised. The parameterisation of these physical processes requires the calibration of some variables. In an early work about parameterisation in distributed models (Refsgaard, 1997), it was demonstrated that the lack of field data means that the calibrated parameters lose their physical basis. Although the losing of their physical meaning, these parameters maintain their inherent variability causing that the best way to estimate their value is, according to Madsen (2003), to use multiple objective functions. In previous works (Mediero et al., 2007, 2011; Garrote et al., 2007), a probabilistic calibration was proposed for distributed models used in flood forecasting. This calibration technique, and the consequent simulated discharge, is dependent on spatial and temporal rainfall resolutions. The optimal horizontal resolution is determined by small scale hydrological processes, such as hillslope processes (Robinson et al., 1996) or catchment processes (Yang et al., 2000), and mesoscale factors associated to convective precipitation which shows a great spatial variability (Barnolas et al., 2010; Marchi et al., 2010). Because of this, it could be concluded that the best horizontal rainfall resolution is the highest one. Temporal variability exhibits a different hydrological behaviour. Some authors have determined a characteristic time scale for hydrological response (Morin et al., 2001), from minutes to hours, while others have found a strong relationship between basin size and the minimum required rainfall spatial and temporal resolutions (Berne et al., 2004). These early studies and more recent ones (Nicótina et al., 2008; Sangati et al., 2009; Anquetin et al., 2010) focused on the temporal-spatial variability relation. However, the main objective of the present work is to study its temporal variability. This variability could be related to concentration time or flow propagation processes. Therefore, discover the optimal rainfall time resolution for a probabilistically calibrated distributed model would be extremely useful to determine the best input rainfall time step for operational purposes.

The goal of this study was to perform a sensitivity analysis of the rainfall time resolution on the results of the RIBS hydrologic distributed model. For this purpose, the WPMM methodology is applied to obtain the best $\mathrm{Z} / \mathrm{R}$ relation. The advection correction scheme allows for the downscaling of radar imagery from several minutes to one minute and is simultaneously used to improve the rainfall estimation. The RIBS model is calibrated for the Besòs River Basin for different time resolutions, and a sensitivity analysis of the rainfall time resolution is performed.

\section{RIBS hydrologic model}

The Real-time Interactive Basin Simulator (RIBS) is a topography-based, rainfall-runoff model that can be used for real-time flood forecasting in midsize and large basins (Garrote and Bras, 1995a,b). The use of this model is especially 
attractive when spatially distributed rainfall is available, e.g. rainfall observed by a weather radar or from meteorological forecasts of spatial rainfall.

The RIBS model is largely based on the detailed topographical information provided by digital elevation models (DEM). Basin representation adopts the rectangular grid of the DEM and other soil properties. Input data and state variables are also represented as data layers using the same scheme. The basic objective is to map the topographically driven evolution of saturated areas as the storm progresses. Two modes of runoff generation are simulated: infiltration excess runoff and saturation excess surface runoff. RIBS applies a kinematic model of infiltration to evaluate local runoff generation at each grid element and also accounts for lateral moisture flow between elements in a simplified manner.

Saturated hydraulic conductivity is assumed to increase with depth, following the relation

$K_{S_{y}}(y)=K_{0 n} \cdot e^{-f y}$

where $K_{0 n}\left[\mathrm{~mm} \mathrm{~h}^{-1}\right]$ is the saturated hydraulic conductivity at the surface in the direction normal to the surface, $y$ [mm] is the depth in the direction normal to the surface and $f\left[\mathrm{~mm}^{-1}\right]$ is a parameter that controls the reduction of saturated hydraulic conductivity with depth. There is an anisotropy between the hydraulic conductivity in the directions that are normal and parallel to the soil surface described by the anisotropy ratio $\alpha$ :

$\alpha=\frac{K_{0 p}}{K_{0 n}}$

where $K_{0 p}\left[\mathrm{~mm} \mathrm{~h}^{-1}\right]$ is the saturated hydraulic conductivity at the surface in the direction parallel to the surface.

Flow propagation to the basin outlet is computed through a distributed convolution using a Dirac delta function as an instantaneous response function for each element, with a delay equal to the time of travel from the location of the element to the basin outlet.

To obtain the travel time to the basin outlet, the velocities for the hillslope $\left(v_{\mathrm{h}}\right)$ and stream $\left(v_{\mathrm{s}}\right)$ must be defined. Stream velocity is assumed to depend on the discharge at the basin outlet:

$v_{\mathrm{S}}(t)=C_{\mathrm{v}}\left(\frac{Q(t)}{Q_{\text {ref }}}\right)^{r}$

where $v_{\mathrm{s}}(t)\left[\mathrm{m} \mathrm{s}^{-1}\right]$ is the stream velocity at time $t, Q_{\text {ref }}$ is a reference flow rate $\left[\mathrm{m}^{3} \mathrm{~s}^{-1}\right], Q(t)$ is the discharge $\left[\mathrm{m}^{3} \mathrm{~s}^{-1}\right]$ at the basin outlet and time $t$ and $C_{\mathrm{v}}\left[\mathrm{m} \mathrm{h}^{-1}\right]$ and $r$ are parameters. If the $r$ parameter is taken equal to zero, $v_{\mathrm{s}}$ parameter is constant throughout the simulation. For $r>0$ and $Q(t)>Q_{\text {ref }}$, the channel velocity is greater than the parameter $C_{\mathrm{v}}$.

The hillslope velocity is related to the stream velocity through the parameter $K_{\mathrm{V}}$ :

$K_{\mathrm{V}}=\frac{v_{\mathrm{s}}(t)}{v_{\mathrm{h}}(t)}$

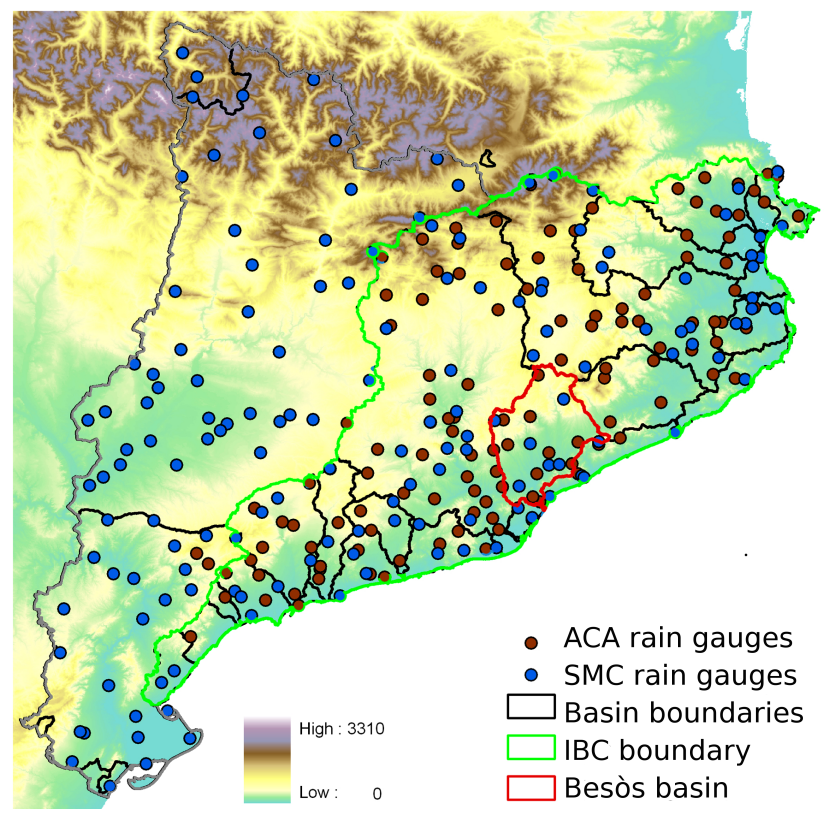

Fig. 1. Location map of Catalonia with superimposed relief and boundary information, together with SAIH (ACA) and XEMA (SMC) raingauge networks.

where $v_{\mathrm{h}}(t)\left[\mathrm{m} \mathrm{s}^{-1}\right]$ is the hillslope velocity at time $t$ and $K_{\mathrm{V}}$ is a parameter.

The model captures the main features of runoff generation processes in a watershed, while maintaining computational efficiency for real-time use.

\section{Case studies and data}

Catalonia is a region situated in the northeast corner of the Iberian Peninsula. Due to its proximity to the warm Mediterranean Sea and its complex orography, with several mountain ranges parallel to the coastline (Fig. 1), the presence of atmospheric instability usually produces intense precipitation events during the summer and autumn seasons (Llasat et al., 2003). These heavy rainfall phenomena caused 217 floods over Catalonia from 1901 to 2000, of which more than $59 \%$ were flash flood events (Barnolas and Llasat, 2007). The hydrologic timescale of most watersheds is on the order of a few hours, and flash floods develop rapidly during the early autumn season and suddenly inundate urban streams, putting citizens at high risk.

One of the most prone basins in Catalonia is the Besòs Basin (Fig. 1). The Besòs catchment $\left(1020 \mathrm{~km}^{2}\right)$ is located to the north of Barcelona over one of the most densely populated watersheds in Catalonia, with more than two million people living in the area. It is a typical example of a complex Mediterranean catchment, possessing great heterogeneity, from mountains over $1000 \mathrm{~m}$ high, to rural plains that have been undergoing a continuous urbanisation process over 


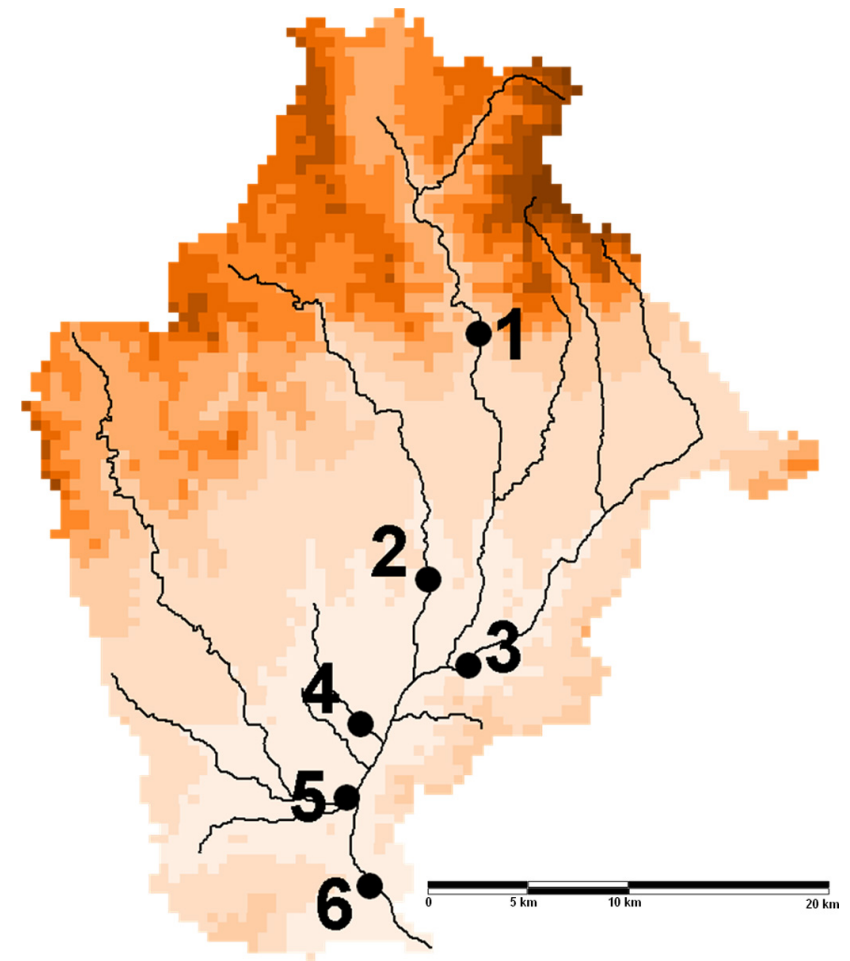

Fig. 2. Location of the river gauging stations within the Besos basin: 1-Garriga; 2-Lliça; 3-Mogent; 4-Mogoda; 5-Montcada; 6Gramenet.

recent decades. After two catastrophic floods in Spain in 1982, considerable investment was devoted to monitoring the catchments for hydrological purposes. It is now instrumented by several telemetered rain and streamflow gauges from SAIH (Automatic System of Hydrological Information) of the Catalan Water Agency (ACA, hereinafter) to a river park built in the river mouth to mitigate flood impacts.

The present work analyses four flash flood events with great social impact (Llasat et al., 2008) that were studied within the framework of the FLASH project (Price et al., 2011). The most relevant rainfall amounts for these cases are detailed in Table 1. For each case, rainfall amounts over the Besòs Basin higher than $46 \mathrm{~mm}$ were recorded. The peak 5 -min intensities during these events range from $80 \mathrm{~mm} \mathrm{~h}^{-1}$ to $135 \mathrm{~mm} \mathrm{~h}^{-1}$.

The available ground rainfall data come from two different networks. The SAIH rain gauge network of the ACA is composed of 126 tipping-bucket automatic rain gauges covering an area of about $16000 \mathrm{~km}^{2}$ called the Internal Basins of Catalonia (IBS) (Fig. 1). The precipitation is accumulated and recorded every $5 \mathrm{~min}$. In this study, all of the 5min series were subject to data quality control (Ceperuelo and Llasat, 2004). The second network, called XEMA (Automatic Weather Station Network) is supported by the Catalan Meteorological Service (SMC, hereinafter) and is composed of 158 rain gauges and covers all of Catalonia (around
Table 1. Rainfall amount and intensity for the four study events over the entire domain of Catalonia and over the Besòs Basin.

\begin{tabular}{lrrrrr}
\hline \multirow{2}{*}{ Data } & \multicolumn{2}{c}{$\begin{array}{c}\text { Max. rainfall } \\
\text { amount }(\mathrm{mm})\end{array}$} & & \multicolumn{2}{c}{$\begin{array}{c}\text { Max. rainfall } \\
\text { intensity }(\mathrm{mm} / \mathrm{h})\end{array}$} \\
\cline { 2 - 3 } \cline { 6 - 7 } & Catalonia & Besòs & & Catalonia & Besòs \\
\hline $2 / 08 / 2005$ & 57.1 & 55.0 & & 117.6 & 117.6 \\
$11-13 / 10 / 2005$ & 348.2 & 81.7 & & 129.6 & 108.0 \\
$13-15 / 11 / 2005$ & 148.1 & 46.4 & & 118.8 & 80.4 \\
$12-14 / 09 / 2006$ & 266.1 & 117.6 & & 249.6 & 135.6 \\
\hline
\end{tabular}

$32114 \mathrm{~km}^{2}$ ). This network records the precipitation in two different temporal intervals. There are 47 stations that accumulate the precipitation every $30 \mathrm{~min}$, while the remaining 111 stations have one-hour temporal resolution.

An straightforward merging of both networks produces a loss in temporal resolution ( $1 \mathrm{~h}$ ) and a density of about 1 rain gauge per $100 \mathrm{~km}^{2}$, which is insufficient to reproduce the spatial pattern of most storms (Corral et al., 2001). Consequently, radar information is essential to simulate flash floods. In this work, the ACA network was used to compute the new Z/R relationship, whereas the SMC network was used to verify the results.

The radar rainfall estimation was implemented using data from the SMC radar network, which covers an area of $53000 \mathrm{~km}^{2}$ over Catalonia and its surroundings. This network is made up of three C-band Doppler radars; a new radar was inaugurated in September 2008 but was not used in this study. The most important characteristics of the composed CAPPI imagery are the spatial resolution $\left(2 \times 2 \mathrm{~km}^{2}\right)$, time resolution $(6 \mathrm{~min})$ and vertical resolution $(1 \mathrm{~km})$ from $1 \mathrm{~km}$ to $10 \mathrm{~km}$ of altitude (10 levels). The CAPPI are calculated by means of the IRIS program, which is based on the linear interpolation of the range to the selected heights in spherical coordinates, with a correction for the Earth curvature to preserve data quality. The radar imagery was corrected using SMC by first passing a filter to remove ground clutter (Bech et al., 2003). A second filter was applied to remove the interference between radars (no data in radar location) and from other non moving targets, such as a wind power plant.

The hydrological data were taken from a stream-flow gauge network composed of 100 stations from which six are located in the Besòs Basin (Fig. 2). The catchment is well covered by the SMC radar (overlap of three radar domains). Other necessary data for the hydrological model include the digital elevation model and soil type, which have been provided by the Cartographic Institute of Catalonia (ICC) with a $200 \mathrm{~m} \times 200 \mathrm{~m}$ resolution. The function of this geomorphologic data will be explained in the Methodology section. 


\section{Methodology}

The proposed methodology was used to perform a sensitivity analysis of the rainfall time resolution, on the results of a hydrologic model in a flash-flood prone basin. As a distributed hydrologic model is selected to better incorporate spatial variations of rainfall in time, spatially distributed rainfall maps for different time resolutions were obtained from the 6-min weather radar data. The calibrated hydrologic model was run taking these estimated rainfall maps as input to determine the time resolution that best represents the hydrological behaviour of the basin.

The methodology is divided into two parts. The first part involves the estimation of the radar rainfall maps for different time resolutions. The second part concerns the probabilistic calibration of the RIBS hydrologic model and the sensitivity analysis of the rainfall time resolution to the results of the calibrated RIBS model.

\subsection{Radar rainfall estimation}

\subsubsection{Method to calculate $Z / R$ relation}

In a previous work (Atencia et al., 2008), a large number of $\mathrm{Z} / \mathrm{R}$ relations were tested for four selected heavy rainfall events. That study showed that radar-based rainfall data underestimated by approximately $18 \%(56 \mathrm{~mm})$, as compared to rain gauge measurements. Consequently, the results were not suitable for hydrological purposes.

To address the issue of QPE, a Z/R relation was obtained by applying the WPMM. This method (Rosenfeld et al., 1994) is based on matching the unconditional probabilities of rainfall and reflectivity. Obviously, point measures from radar and rain gauges are plagued by timing and spatial errors. Many of the timing and geometrical errors can be eliminated by applying the probability matching method using synchronous time series (Rosenfeld et al., 1993). This is achieved by matching rain-gauge intensities to radar reflectivities taken only from small windows centred over the gauges in time and space. Zawadzki (1975) has shown that both the window area $(A)$, in $\mathrm{km}^{2}$, and the spread of the raingauge measurement in time $(T)$, in $\mathrm{h}$, are related as follows:

$T=\frac{1}{3} \cdot \frac{A^{\frac{1}{2}}}{V}$

where $V\left[\mathrm{~km} \mathrm{~h}^{-1}\right]$ represents the horizontal velocity of the rainfall/storm-cell system. Atlas et al. (1990) and Rigo (2004) reported a climatic horizontal velocity of convective rainfall area of about $20 \mathrm{~km} \mathrm{~h}^{-1}$. Thus, a rain gauge time concentration of $6 \mathrm{~min}$ is obtained by applying this formulae (Eq. 5 ) for a $3 \times 3$ pixel window. In this study, the SAIH rain gauge data has a time resolution of $5 \mathrm{~min}$. To ensure an optimal correlation between both radar and rain gauge rainfall measurements (Rosenfeld et al., 1994), the solution is work with a temporal window of $30 \mathrm{~min}$, which is a time interval

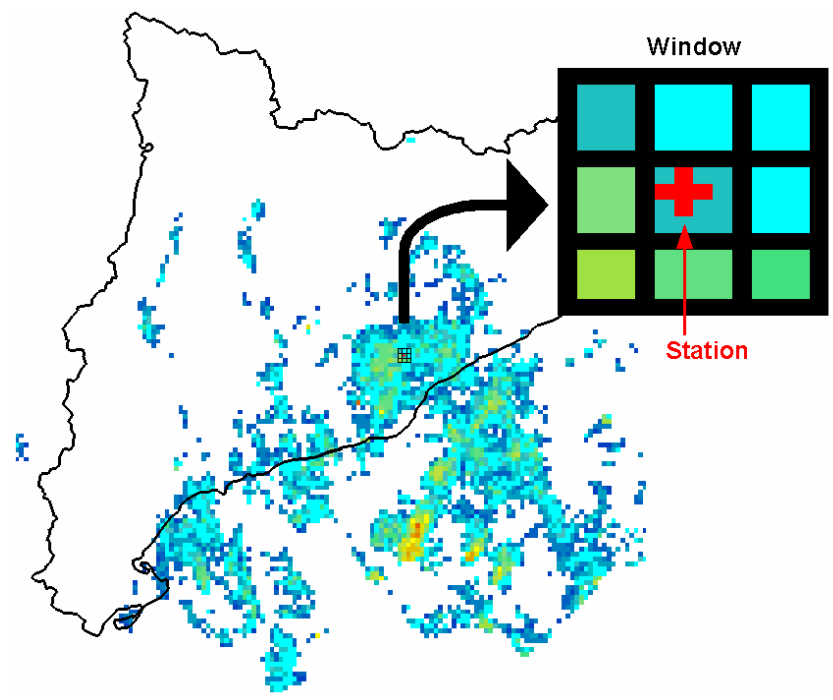

Fig. 3. Radar window example. Square window of $3 \times 3$ pixel dimension is centered over a rain gauge (red cross).

that is greater than the optimal value. To solve this problem the following procedure has been applied:

- First, a radar window $(3 \times 3$ pixels $)$ around the rain gauge is built (Fig. 3).

- Second, each reflectivity's independent window for every period of $30 \mathrm{~min}$ is taken from every pixel (45 in total) coming from five radar windows of each 6-min radar image (Fig. 4b)

- Third, 5-min rainfall intensity for each rain gauge is accumulated in order to obtain rain gauge window for each period of $30 \mathrm{~min}$ (Fig.4a)

Once the overall dataset of the independent windows has been built, the $\mathrm{Z} / \mathrm{R}$ relation can be calculated from a random sub-sample of those data. To reproduce the original method (Rosenfeld et al., 1994), which was used to compute the $\mathrm{Z} / \mathrm{R}$ relationship by comparing quantiles, a non-parametric technique should be used. To avoid problems of tail stability found in the empirical probability distribution function (Kaplan and Meier, 1958), a technique based on a kernel smoothing density function (Parzen, 1962) is applied. To test another smoothed relation, different parametric probability density functions (pdf) were fitted for both rainfall and reflectivity distributions. The ones that maximise the likelihood were exponential functions for rain gauges, whereas the pdf of the reflectivity values was well fitted by a gamma distribution. In Fig. 5, a random sub-sample of $25 \%$ of the overall population of windows is plotted. Although, the distribution does not fit well for reflectivity values below $19 \mathrm{dBZ}$, the contribution of this precipitation (less than $0.1 \mathrm{~mm} \mathrm{~h}^{-1}$ ) can be ignored in comparison with the heavy rainfall recorded. 


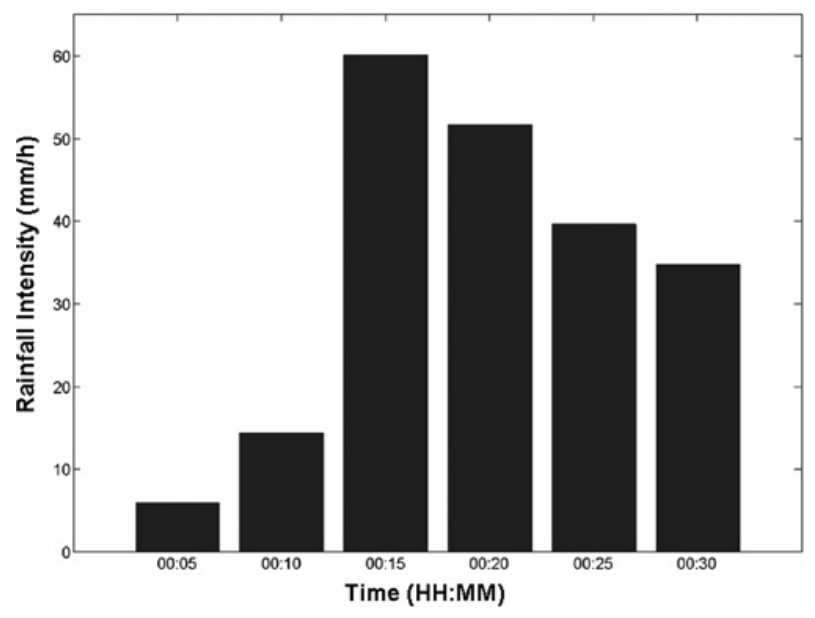

(a) Example of an independent rainfall window dataset: Evolution of 5-min rainfall rate for a period of $30 \mathrm{~min}$.

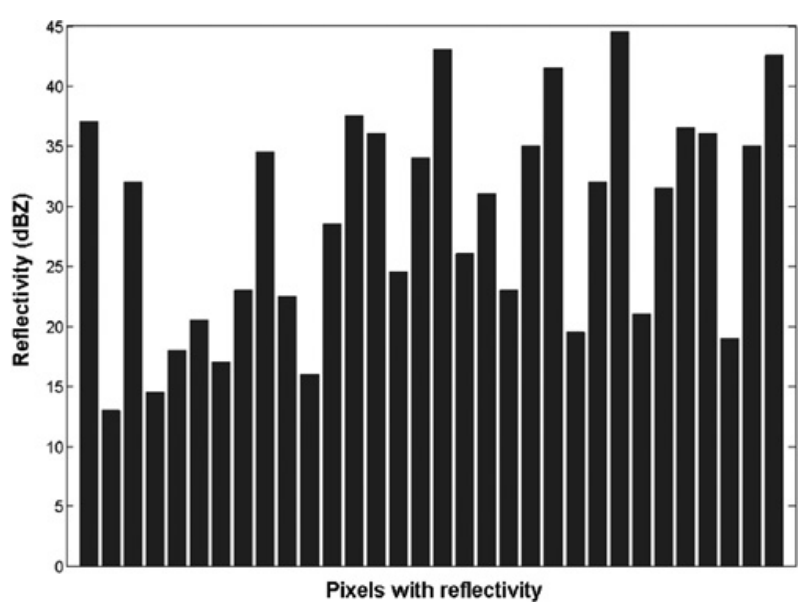

(b) Example of a single independent reflectivity window dataset: 6-min reflectivities for a period of $30 \mathrm{~min}$ (5 radar images) and for the nine pixels comprising a window.

Fig. 4. Examples of a rain gauge (a) and weather radar reflectivity (b) independent window.

(a)

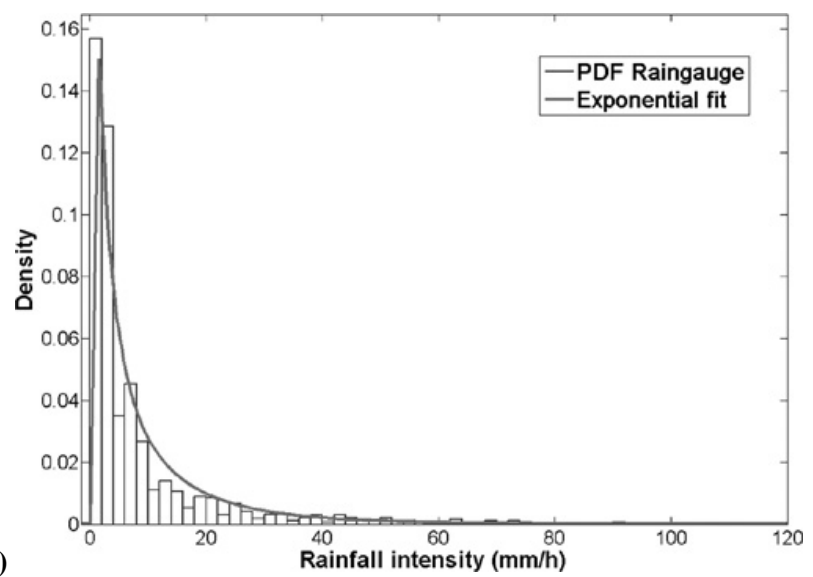

(b)

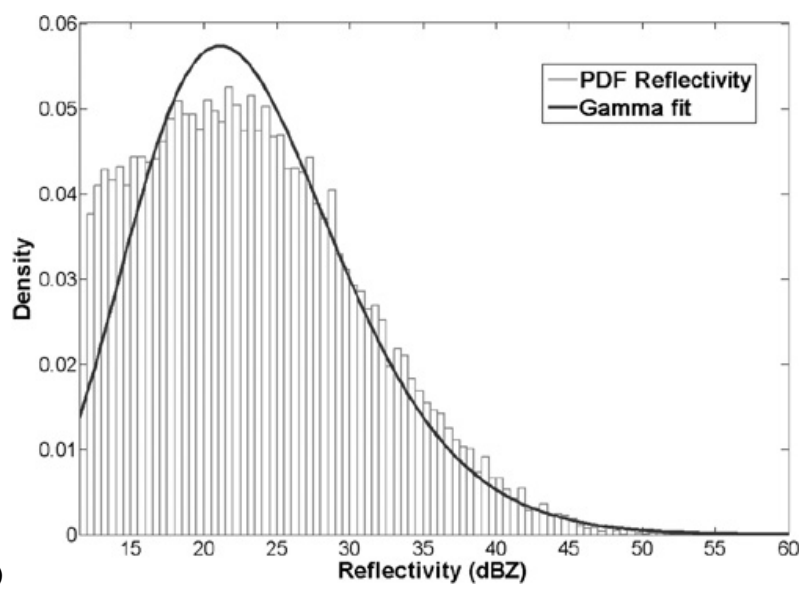

Fig. 5. The left picture (a) shows a density histogram of a random sub-sample of $25 \%$ of the overall population of rain gauge data and the Exponential pdf fit. The right one (b) shows density histogram for radar data window and Gamma pdf fit.

Adapting the $\mathrm{Z} / \mathrm{R}$ relationship to different rain types within a given storm or event seems to be a promising way to improve radar QPE (Lee and Zawadzki, 2005). Rosenfeld et al. (1995) improved the accuracy of WPMM-estimated rainfall by means of objective classification criteria based on parameters such as freezing level or bright-band fraction. In the present work, the classification criteria developed by Biggerstaff and Listemaa (2000) were performed within a 3-D scheme, to recognise convective/stratiform areas (see also Steiner et al., 1995). This algorithm distinguishes between convective and stratiform areas according to reflectivity thresholds and gradients between different CAPPI levels, which were regionalised to Catalonia by Rigo and Llasat (2004). According to this methodology, in the present study, each different subset of every window was counted in different groups. Therefore, for the same rain gauge intensity win- dow, two radar reflectivity windows are set. This approach to the classification criteria results in an ambiguous rain gauge probability distribution function. The ambiguous relation between the intensity and rain type should be subsequently calculated as two independent unambiguous datasets.

Using both parametric and non-parametric techniques, the derivation of the $\mathrm{Z} / \mathrm{R}$ relation is very simple and straightforward. A randomisation process is applied by selecting different sizes of sub-samples to ensure the minimisation of spatial and geometric errors. This process also provides probabilistic information about the convergence of the population to a final relationship. In this way, the standard deviation (SD) is used to evaluate the consistency of the new relation and the range over which the final relation is absolutely sound. 


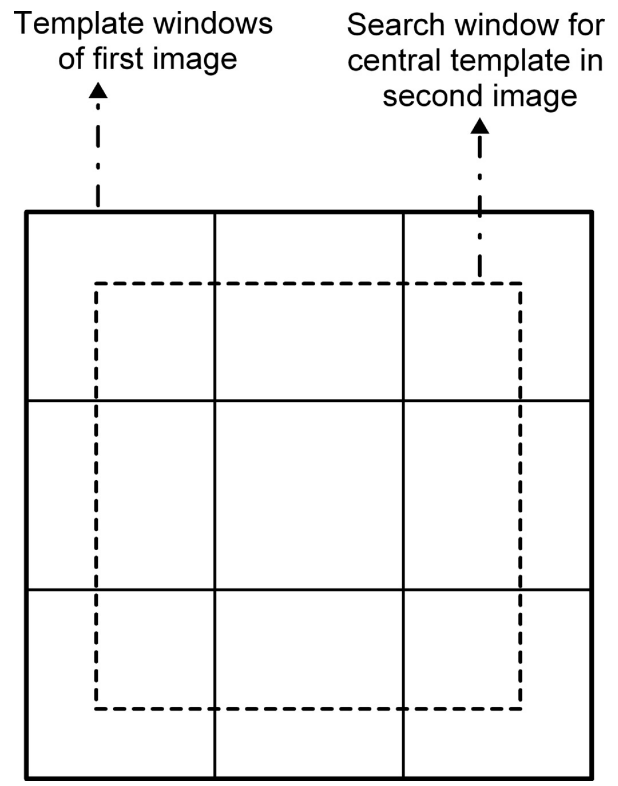

(a) Division of the first image into templates (solid lines) and search area (dashed line) corresponding to the central template.

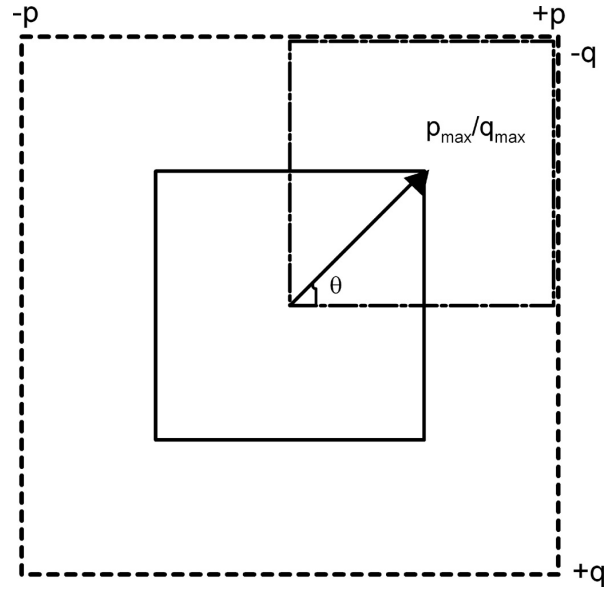

(b) Vector indicating where in the second image the centre of the window (dotted line) closest to the original template (solid line) lies.

Fig. 6. Example of templates in the second image for the cross-correlation technique and the displacement vector obtained. Both pictures, (a) and (b), are extracted from Dransfeld et al. (2006).

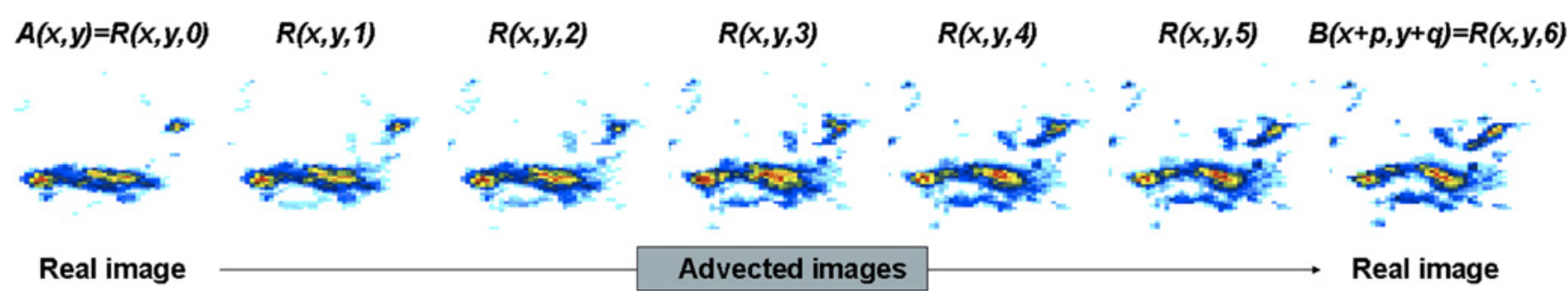

Fig. 7. Real example of radar rainfall disaggregation. In the above example $3 \times 3$ templates are shown in each image. The original resolution is $6 \mathrm{~min}$ and the cross-correlation advection results in a $1 \mathrm{~min}$ resolution.

\subsubsection{Advection correction}

The temporal sampling effect of radar observations can lead to significant errors in the estimated accumulated rainfall as shown in several studies (Liu and Krajewski, 1996; Fabry et al., 1994). To correct for this source of error, Anagnostou and Krajewski (1999) proposed an advection correction method based on cross-correlation maximisation (Rinehart and Garvey, 1978). This procedure can be applied not only to correct for these type of sampling errors, but also to increase the time resolution. For this reason, instead of calculating the cross-correlation coefficient between the two whole images, the first image is divided into a number of template tiles (Fig. 6a). Each template window will be searched for in the second image using a search window (dashed line in Fig. 6a and 6b), whose size depends on the maximum storm speed that is expected between two sequential images. In the present work, this technique was used to obtain the advective displacement vector (vector in Fig. 6b). This displacement $(p, q)$ indicates a storm or cell movement (Dransfeld et al., 2006).

Once the advective displacement vector has been obtained by this method, a shape morphology transformation is performed by means of temporal weights based on a more complex shape transformation (Turk and O'Brien, 2005). Both the first, $A(x, y)$, and second rainfall fields, $B(x, y)$, are interpolated by means of the computed velocity to the same temporal interval. Then, the value of rainfall at location $(x, y)$ and time $t, R(x, y, t)$, is calculated as the temporal-weighted sum of the two images as shown in the next function:

$$
R(x, y, t)=\frac{1}{T^{2}} \cdot \sum\{(T-t) \cdot \widetilde{A}(t)+t \cdot \widetilde{B}(t)\}
$$




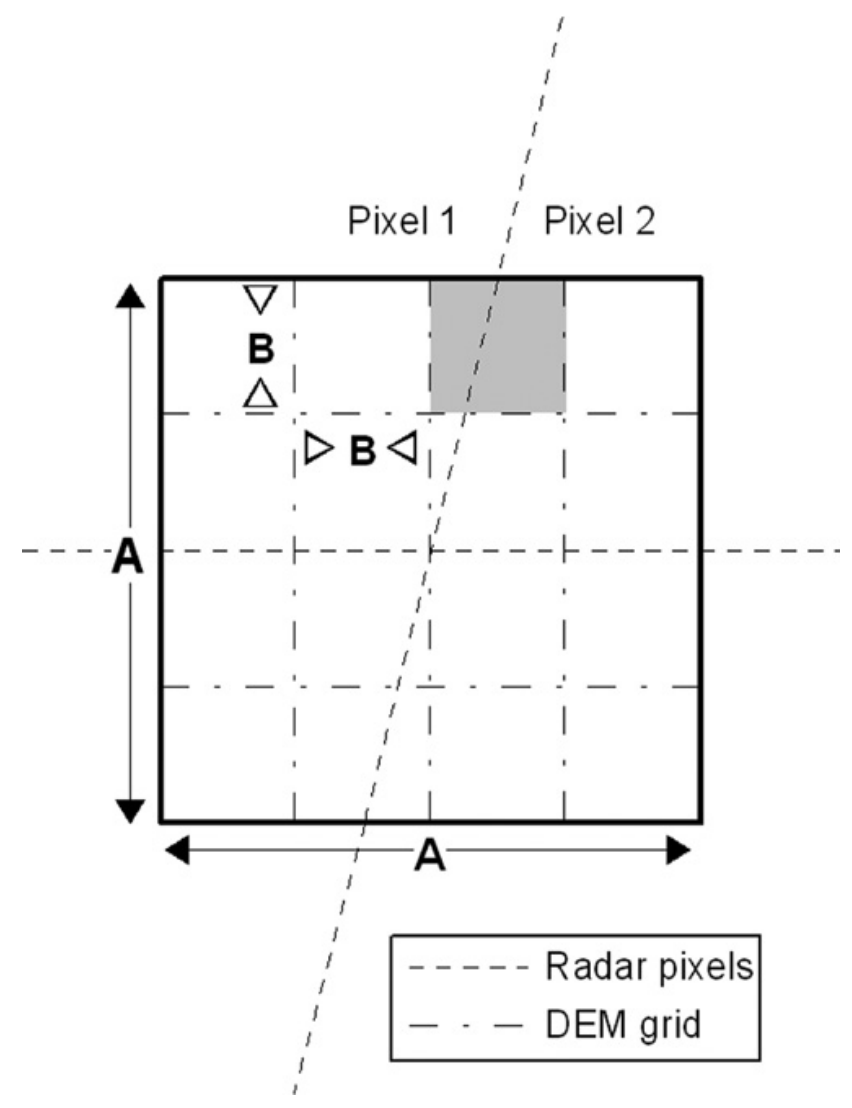

Fig. 8. Superposition of radar pixels over DEM grid over a small domain of area $A^{2}$. The highlighted grey DEM grid pixel is used as example of mismatching between the two grids.

where the transformed fields $\widetilde{A}(x, y, t)$ and $\widetilde{B}(x, y, t)$ are calculated by the functions

$$
\begin{aligned}
& \widetilde{A}(x, y, t)=A\left[x-\frac{t}{T} \cdot c \cdot \cos \theta, y-\frac{t}{T} \cdot c \cdot \sin \theta\right] \\
& \widetilde{B}(x, y, t)=B\left[x+\frac{T-t}{T} \cdot c \cdot \cos \theta, y+\frac{T-t}{T} \cdot c \cdot \sin \theta\right]
\end{aligned}
$$

where $A$ and $B$ are consecutive radar rainfall fields. $c$ is the advective velocity $\left[\mathrm{km} \mathrm{h}^{-1}\right]$ and $\theta$ is the displacement angle. $T[\mathrm{~h}]$ represents the original time resolution of radar and $t$ $[\mathrm{h}]$ is time within the time interval $T$.

The template size selected is $10 \times 8$ pixels, whereas the search window for the second image is $16 \times 14$ pixels. This size was calculated by assuming a maximum storm movement lower than $140 \mathrm{~km} \mathrm{~h}^{-1}$, following the works of Steinacker et al. (2000) and Rigo (2004). Figure 7 shows the downscaling from $6 \mathrm{~min}$ to $1 \mathrm{~min}$.

\subsubsection{Rainfall data into RIBS hydrological model}

The RIBS model requires that rainfall input data be mapped to the rectangular grid of the DEM. As radar images and
DEM resolutions are different and may correspond to different projections, a preliminary treatment of radar images is required.

The main step is an interpolation to downscale the radar resolution grid $(2 \mathrm{~km} \times 2 \mathrm{~km})$ to the DEM resolution $(200 \mathrm{~m} \times 200 \mathrm{~m})$. The easiest and quickest way is to perform an ordinary linear interpolation, but this methodology does not exactly preserve the total amount of precipitation over the whole domain due to mismatching grids (Fig. 8). To avoid this, another procedure was developed in the present work. As shown in Fig. 8, some DEM grid cells are divided into two different reflectivity parts (grey cell). The main purpose of the new procedure is to preserve the total areal precipitation amount, which is achieved by an area-weighted interpolation. This could be formulated in a general way as follows:

$\mathrm{RD}_{j}=\frac{\sum_{i \in I_{j}} S_{j}^{i} R_{i}}{\sum_{i \in I_{j}} S_{j}^{i}}$

where $\mathrm{RD}_{j}$ is rainfall intensity in DEM cell $j, R_{i}$ is rainfall intensity in radar cell $i, I_{j}$ is the set of radar cells that cover DEM cell $j$ and $S_{j}^{i}$ is the area of DEM cell $j$ covered by radar cell $i$.

Once rain rated for every cell of the whole domain has been calculated by this area-weighted interpolation, the Besòs Basin shape is cut out from the high resolution rainfall image.

\subsubsection{Radar rainfall validation}

To evaluate the accuracy of the radar rainfall estimation, three error indexes are calculated. The first one is the log ratio bias (Eq. 10), which is a relative error and provides information about the total amount of precipitation:

$\log$ ratiobias $=\log \cdot \frac{\sum R_{i}}{\sum P_{i}}$

The second is the Root Mean Square Error $\left(\mathrm{RMSE}_{R} ;\right.$ Eq. 11) $[\mathrm{mm}]$, which determines the accuracy of the estimation for each individual rain gauge.

$\operatorname{RMSE}_{R}=\sqrt{\frac{\sum\left(R_{i}-P_{i}\right)^{2}}{n}}$

The third is the Mean Error ( $\mathrm{ME}_{R}$; Eq. 12) [mm], which defines whether the rainfall is under/over-estimated.

$\mathrm{ME}_{R}=\frac{\sum\left(R_{i}-P_{i}\right)}{n}$

Here, $R_{i}$ and $P_{i}$ are the rainfall amount at location $i$ derived from the radar and registered by SMC rain gauges, respectively. The value $n$ represents the total number of valid points. 


\subsection{Hydrological modeling}

\subsubsection{Selection of rainfall time resolutions}

Spatially distributed precipitation maps can be constructed for each event by summing the new advected 1-min radar rainfall maps to a given resolution. A set of time resolutions must be selected to perform the analysis.

The required minimum time resolution of rainfall for Mediterranean regions can be estimated as a function of the basin area (Eq. 13), taking into account that time resolutions higher than 3 min only become relevant for basin areas smaller than $100 \mathrm{ha}\left(1 \mathrm{~km}^{2}\right)$ (Berne et al., 2004).

$\Delta t=0.75 \cdot S^{0.3}$

where $\Delta t$ is the required minimum time resolution [min], and $S$ is the basin area [ha].

\subsubsection{Probabilistic calibration}

The distributed RIBS model was calibrated using a probabilistic approach based on a multiobjective calibration methodology, since both different aspects of the hydrograph and the uncertainty in the hydrologic model estimations may be taken into account. The calibration result is a pdf for each calibrated model parameter (Mediero et al., 2011).

The probabilistic calibration methodology can be summarised as follows. First, a sensitivity analysis was performed over the global parameters of the RIBS model, since the local parameters, as $K_{0 n}$, were estimated from the soil types in the basin prior to the calibration. As model input observed rainfall data in the first event at a 15 min time resolution was used, and model parameter values were randomised from uniform distributions. A modification of the Generalised Sensitivity Analysis (GSA) methodology proposed by Freer et al. (1996) was applied. This analysis showed that the most influential parameters in the model output are as follows: the rate of variation of the hydraulic conductivity in depth $(f)$, the soil anisotropy coefficient $(\alpha)$, the ratio of hillslope flow velocity to channel flow velocity $\left(K_{\mathrm{v}}\right)$ and the coefficient of the law that relates hillslope flow velocity to discharge in the basin outlet $\left(C_{\mathrm{v}}\right)$.

Second, the proper calibration methodology was performed over the first three recorded events for each rainfall time resolution. A large set of synthetic hydrographs was generated by repetitive simulations of the RIBS model; these simulations generated randomised sets of values for the most influential model parameters, which were identified in the first step. Hydrological model outputs highly depend on the initial basin conditions. Therefore, the antecedent moisture content in the basin is an input of the RIBS model and it was estimated from rainfall and temperature data in the days before the beginning of each flood event. As the model utilisation is the prediction of flash floods, the Root Mean Square Error (RMSE; Eq. 14), Mean Absolute Error (MAE; Eq. 16) and Nash-Sutcliffe Efficiency Coefficient
(NSE; Eq. 17) were selected as objective functions to conduct the multiobjective calibration.

$$
\begin{aligned}
& \mathrm{RMSE}=\sqrt{\frac{1}{T_{\mathrm{s}}} \sum_{t=1}^{T_{\mathrm{s}}}\left(Q_{\mathrm{o}}^{t}-Q_{\mathrm{s}}^{t}\right)^{2}} \\
& \mathrm{ME}_{H}=\sum_{t=1}^{T_{\mathrm{s}}}\left(Q_{\mathrm{o}}^{t}-Q_{\mathrm{s}}^{t}\right) \\
& \mathrm{MAE}=\sum_{t=1}^{T_{\mathrm{s}}}\left|\left(Q_{\mathrm{o}}^{t}-Q_{\mathrm{s}}^{t}\right)\right| \\
& \mathrm{NSE}=1-\frac{\sum_{t=1}^{T_{\mathrm{s}}}\left[Q_{\mathrm{o}}^{t}-\overline{Q_{\mathrm{s}}}\right]^{2}}{\sum_{t=1}^{T_{\mathrm{s}}}\left[Q_{\mathrm{o}}^{t}-\overline{Q_{\mathrm{o}}}\right]^{2}}
\end{aligned}
$$

where $Q_{\mathrm{o}}^{t}$ is the observed discharge at time $t, Q_{\mathrm{s}}^{t}$ is the simulated discharge at time $t, \overline{Q_{\mathrm{o}}}$ is the mean of observed discharges, $\overline{Q_{\mathrm{s}}}$ is the mean of simulated discharges and $T_{\mathrm{s}}$ is the total number of time steps.

In a multiobjective calibration, no single solution can minimise all of the objective functions at the same time (Gupta et al., 1998). Therefore, the Pareto solutions were identified to determine the set of non-inferior solutions (Yapo et al., 1998). Each calibrated model parameter was represented by a pdf fitted from the set of Pareto solutions for the three calibration events. The distribution functions that best fit the variability of each parameter were identified by means of traditional goodness-of-fit tests, i.e. Chi-Squared test and Kolmogorov-Smirnov test.

\subsubsection{Sensitivity analysis of the rainfall time resolution}

The result of the probabilistic calibration of the RIBS model is a pdf for each parameter, which represents the parameter's variability. Therefore, the result of the model calibration is not a single hydrograph, but an ensemble distribution hydrographs. This ensemble is obtained by the randomisation of the model parameter values based on the calibration results. The number of hydrographs used to analyse the importance of time resolution must be large enough to reach the stabilisation of the model results. The required number of simulations was defined through a sensitivity analysis, which established that 200 model simulations were required to obtain reliable results.

A sensitivity analysis of the rainfall time resolution was performed for the last observed event. Differences between the simulated set of hydrographs and the observed hydrograph were quantified by four measures. RMSE and Mean Error $\left(\mathrm{ME}_{H}\right)$ were selected to measure the accuracy of the simulations (Eq. 14-15).

Two other measures were added to improve the assessment. The estimation bias was quantified by a modification 
Table 2. Validation results for the eight $\mathrm{Z} / \mathrm{R}$ relationships in each of the four study cases. The numbers in the second row represent the pdf fitting method, being 1 exponential-Gamma and 2 for the Kernel smoothing density function.

\begin{tabular}{|c|c|c|c|c|c|c|c|c|c|}
\hline \multirow[b]{2}{*}{ Calibration } & \multirow[t]{2}{*}{ Validation } & \multicolumn{2}{|c|}{ August 2005} & \multicolumn{2}{|c|}{ October 2005} & \multicolumn{2}{|c|}{ November 2005} & \multicolumn{2}{|c|}{ September 2006} \\
\hline & & 1 & 2 & 1 & 2 & 1 & 2 & 1 & 2 \\
\hline \multirow{3}{*}{ August 05} & BIAS & 0.28 & 0.13 & 0.07 & -0.17 & 0.03 & -0.19 & -0.09 & -0.30 \\
\hline & $\mathrm{ME}_{R}$ & 6.89 & 3.28 & 4.78 & -21.99 & 17.96 & -5.61 & -17.90 & -45.30 \\
\hline & $\mathrm{RMSE}_{R}$ & 1.64 & 1.30 & 1.89 & 2.39 & 4.78 & 4.03 & 3.38 & 4.29 \\
\hline \multirow{3}{*}{ October 05} & BIAS & 0.33 & 0.32 & 0.02 & -0.09 & -0.03 & -0.13 & -0.12 & -0.19 \\
\hline & $\mathrm{ME}_{R}$ & 10.09 & 12.64 & -1.83 & -12.81 & 7.92 & 3.51 & -21.30 & -30.58 \\
\hline & $\mathrm{RMSE}_{R}$ & 1.88 & 2.35 & 1.73 & 1.98 & 4.10 & 4.64 & 3.28 & 3.57 \\
\hline \multirow{3}{*}{ November 05} & BIAS & 0.21 & 0.19 & -0.09 & -0.19 & -0.14 & -0.23 & -0.23 & -0.31 \\
\hline & $\mathrm{ME}_{R}$ & 4.19 & 4.94 & -16.85 & -25.12 & -9.34 & -12.65 & -39.10 & -46.58 \\
\hline & $\operatorname{RMSE}_{R}$ & 1.12 & 1.26 & 2.09 & 2.40 & 3.26 & 3.72 & 3.88 & 4.22 \\
\hline \multirow{3}{*}{ September 06} & BIAS & 0.45 & 0.41 & 0.17 & 0.02 & 0.13 & -0.02 & 0.02 & -0.09 \\
\hline & $\mathrm{ME}_{R}$ & 17.06 & 19.67 & 24.09 & 3.62 & 36.84 & 25.67 & 6.84 & -11.37 \\
\hline & $\mathrm{RMSE}_{R}$ & 2.84 & 3.52 & 2.28 & 2.04 & 6.43 & 6.64 & 3.33 & 3.34 \\
\hline
\end{tabular}

of the Nash-Sutcliffe global efficiency index $\left(R^{2}\left(\mathrm{MQ}_{0.5}\right)\right.$; Eq. 18), which measures the utility of the median, instead of the mean, as a forecast (Xiong and O'Connor, 2008).

$R^{2}\left(\mathrm{MQ}_{0.5}\right)=1.0-\frac{\sum_{t=1}^{T_{\mathrm{s}}}\left[Q_{\mathrm{o}}^{t}-\mathrm{MQ}_{0.5}^{t}\right]^{2}}{\sum_{t=1}^{T_{\mathrm{s}}}\left[Q_{\mathrm{o}}^{t}-\overline{Q_{\mathrm{o}}}\right]}$

where $\mathrm{MQ}_{0.5}^{t}$ is the median of simulated discharges at time $t$.

The predictive capability of the calibrated model was quantified by the Containing Ratio (CR; Eq. 19), which measures the number of observations that fall within the prediction interval linked to a given confidence level (Montanari, 2005).

$\mathrm{CR}(\alpha)=\frac{\sum I\left[Q_{\mathrm{o}}^{t}\right]}{T_{\mathrm{S}}}$

where $I\left[Q_{\mathrm{o}}^{t}\right]$ is equal to 1 if the observed discharge at time $t$ holds between the confidence interval, and $\alpha$ is the confidence level, which was set at $10 \%$.

\section{Results}

\subsection{WPMM methodology}

The four selected heavy rainfall events were produced by very different meteorological events. For this reason, the calibration method previously presented was applied for each case such that eight $\mathrm{Z} / \mathrm{R}$ relations were obtained: two fitting methods for each of the four case studies. In Table 2, error indices are presented for the eight functions, which are compared for every case using the total event amount in the comparison.
Regarding the comparison of both methodologies, it can be observed that a parametric fit (exponential-Gamma) improves results compared to a non-parametric fit (Fig. 9). The left box plot for a given fitting methodology, represents the results for the $\mathrm{Z} / \mathrm{R}$ obtained for the same study case, whereas the right box plot shows the $\mathrm{Z} / \mathrm{R}$ results computed for the three other case studies. The log ratio bias and the $\mathrm{RMSE}_{R}$ show better results for both box plot regarding the mean and the interquartile range. It can be observed that, in general, best results are obtained for the left box plots. Nevertheless, as the results show, also for the other three events calibrated fits achieve accurate precipitation estimations.

A comparison between both methodologies shows that the parametric fit improves the range of applicability of the new $\mathrm{Z} / \mathrm{R}$ relationship. It can be observed in Fig. 10 that the SD is higher for the tails of the non-parametric $\mathrm{Z} / \mathrm{R}$ relation (Fig. 10a) than for the parametric Z/R relation (Fig. 10b). This is caused by the scarcity of values in the tails of the probability distribution function for the reflectivity and high intensity rainfall values. The parametric fit does not have this problem because it has only two parameters to compute, and this computation gives more weight to the central values of the distribution.

\subsection{Advection correction}

Table 3 shows the results of applying the advection technique to the best rainfall estimation method. The use of a crosscorrelation technique to interpolate the rain improved the results previously obtained for the root mean square error and mean error for all of the cases; however, it did not change the total radar rainfall field as can be observed for the BIAS values. 
Table 3. Comparison of results before and after applying the advection correction.

\begin{tabular}{lrrrrrrr}
\hline & \multicolumn{3}{c}{ Best previous results } & & \multicolumn{3}{c}{ Advection results } \\
\cline { 2 - 3 } \cline { 7 - 8 } Index & \multicolumn{1}{c}{ BIAS } & $\mathrm{ME}_{R}$ & $\mathrm{RMSE}_{R}$ & & BIAS & $\mathrm{ME}_{R}$ & $\mathrm{RMSE}_{R}$ \\
\hline Aug 05 & -0.04 & -1.1 & 1.00 & & 0.002 & -0.59 & 0.92 \\
Oct 05 & 0.02 & -1.83 & 1.73 & & 0.02 & -1.50 & 1.70 \\
Nov 05 & -0.13 & 3.51 & 3.26 & & -0.14 & 3.06 & 3.23 \\
Sep 06 & 0.02 & 6.84 & 3.33 & & 0.02 & 4.20 & 2.99 \\
\hline
\end{tabular}

Table 4. Basin area $\left(\mathrm{km}^{2}\right)$, length of the main watercourse $(\mathrm{km})$, slope between maximum and minimum elevation $(\mathrm{m} / \mathrm{m})$, time of concentration by the Kirpich formula $(h)$ and required minimum time resolution of rainfall in Mediterranean regions (min) of Besòs basin stations.

\begin{tabular}{lrrrrr}
\hline Station & Area $\left(\mathrm{km}^{2}\right)$ & $\mathrm{L}(\mathrm{km})$ & $\mathrm{S}(\mathrm{m} / \mathrm{m})$ & $t_{c}(h)$ & $\Delta t_{\min }[\mathrm{min}]$ \\
\hline Mogoda & 111 & 31.83 & 0.026 & 3.87 & 12.3 \\
Lliça & 146 & 38.71 & 0.023 & 4.73 & 13.3 \\
Garriga & 151 & 26.41 & 0.026 & 3.36 & 13.5 \\
Mogent & 182 & 36.66 & 0.032 & 3.99 & 14.2 \\
Montcada & 221 & 43.24 & 0.015 & 6.15 & 15.1 \\
Gramenet & 1012 & 63.45 & 0.015 & 8.26 & 23.8 \\
\hline
\end{tabular}

The impact of the advection can be observed in Fig. 11. The maximum values and the shape of the rainfall field has changed for this specific example. Regarding the improvement in the hourly accumulated rainfall, Fig. 12 compares the log ratio bias and the $\mathrm{RMSE}_{R}$ of the QPE before and after applying the advection correction technique.

\subsubsection{Selection of rainfall time resolutions}

The minimum time resolution for the gauging stations in the Besòs Basin calculated using Eq. (13) are included in Table 4 . It can be seen that they are within 12 to $24 \mathrm{~min}$. Therefore, the calibration of the RIBS model was performed for six time resolutions: 30, 24, 18, 15, 12 and 6 min. Resolutions higher than $6 \mathrm{~min}$ were not considered because this greatly increases the computation time of the RIBS model. Moreover, these time resolutions are not relevant for the basin areas considered in the Besòs Basin.

\subsection{Hydrologic model calibration}

The distributed RIBS model was calibrated in the Besòs Basin with the first three observed events. The basin shape and the locations of the gauging stations are shown in Fig. 2, and their basic properties are presented in Table 4 . The model was calibrated using data from the Gramenet station, very near the basin outlet. Spatially distributed precipitation maps were constructed for each event by summing the new advected radar rainfall estimation for 30,24, 18, 15, 12 and $6 \mathrm{~min}$. The antecedent moisture content was used as an input
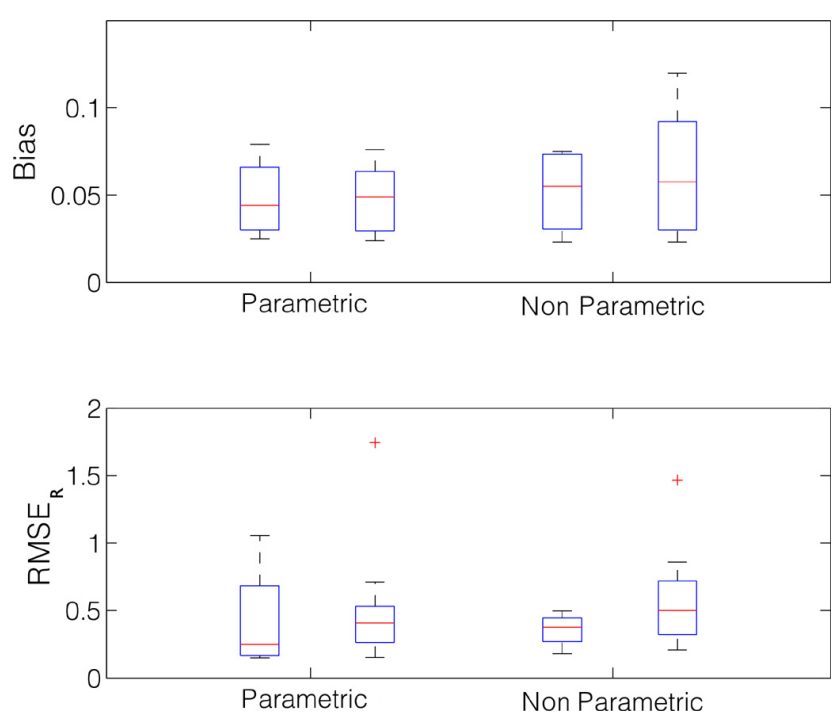

Fig. 9. Box-plot of both fitting techniques (parametric and nonparametric) for the log ratio bias and the $\operatorname{RMSE}_{R}$. The left boxplot for a given fitting methodology represents the results for the $\mathrm{Z} / \mathrm{R}$ obtained for the same study case whereas the right box plot is the results obtained for the $\mathrm{Z} / \mathrm{R}$ computed by the three other case studies.

in the RIBS model from rainfall and temperature data in the days before the flood event.

The calibration methodology was conducted for each rainfall time resolution to take into account the fact that some hydrological parameters may be dependent on the time scale. The calibration results are summarised by the main statistics of the distribution of parameter values for each time resolution (Table 5).

\subsection{Sensitivity to precipitation time resolution}

A sensitivity analysis of the rainfall time resolution was carried out for the last event, at each of the six gauging stations: Lliça station on the Tenas River, Montcada Station on the Ripoll River, just upstream of its confluence with the Besòs River, Gramenet Station on the Besòs River, very near the basin outlet, Garriga Station on the Congost River, Mogent Station on the Mogent River and Mogoda Station on the Caldas River (Fig. 2).

A set of 200 simulated hydrographs was generated for each time resolution. These simulated hydrographs were compared with the observed flows for each gauge as described in Sect. 4.2.3; the results obtained are presented in Table 6 and Figs. 13 and 14.

The predictive capability of the peak discharge with a significance level of $10 \%$ is presented as a function of rainfall time resolution in Fig. 13. The range between confidence limits is represented by the length of the error bars. Most stations show smallest variability and best fit between the median simulated and the observed value for time resolutions 


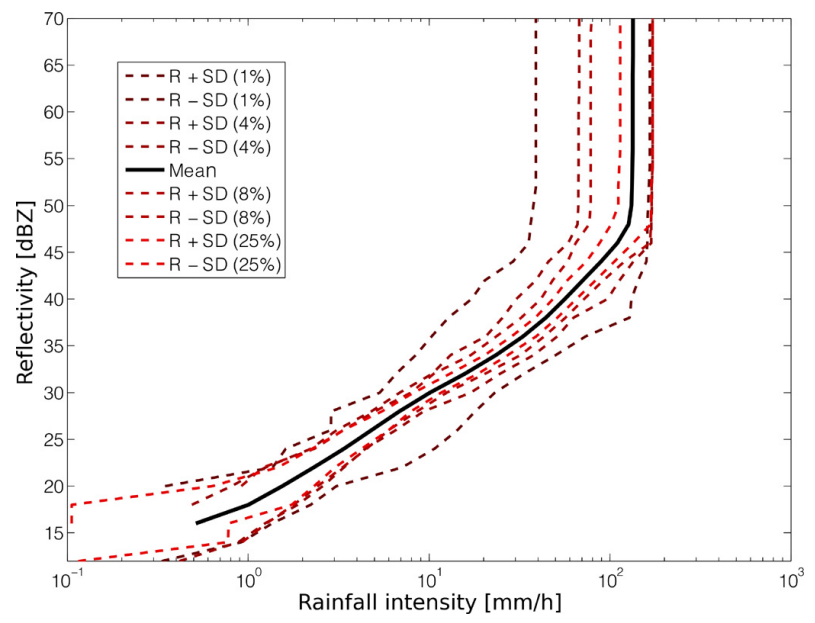

(a) Non-parametric

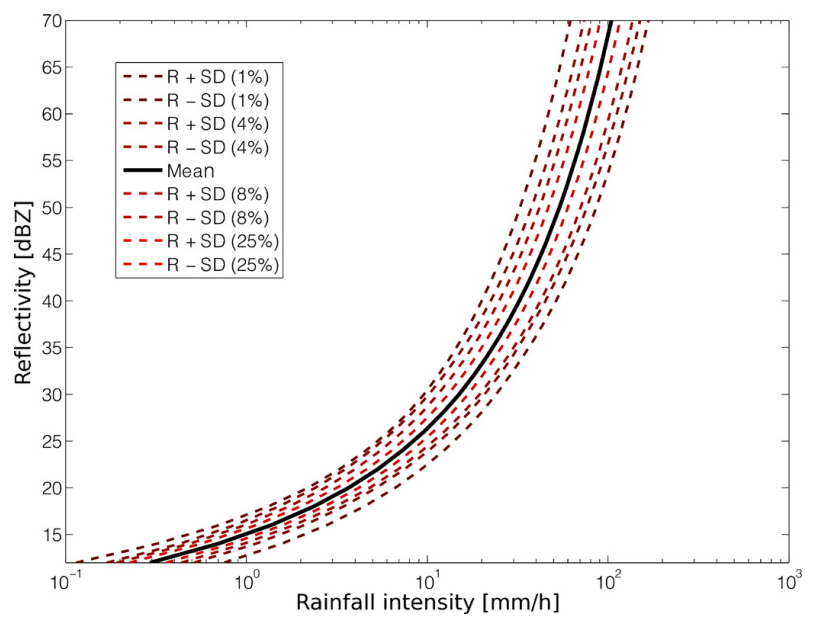

(b) Parametric

Fig. 10. The new $\mathrm{Z} / \mathrm{R}$ relation (solid middle line), as obtained from WPMM for the full dataset. The broken lines represent plus and minus one standard deviations from the Z/R when calculated by population from $1 \%$ to $25 \%$ sub-samples. The left example (a) is the new Z/R relation obtained by non-parametric fitting whereas the right one (b) correspond to the parametric fit.

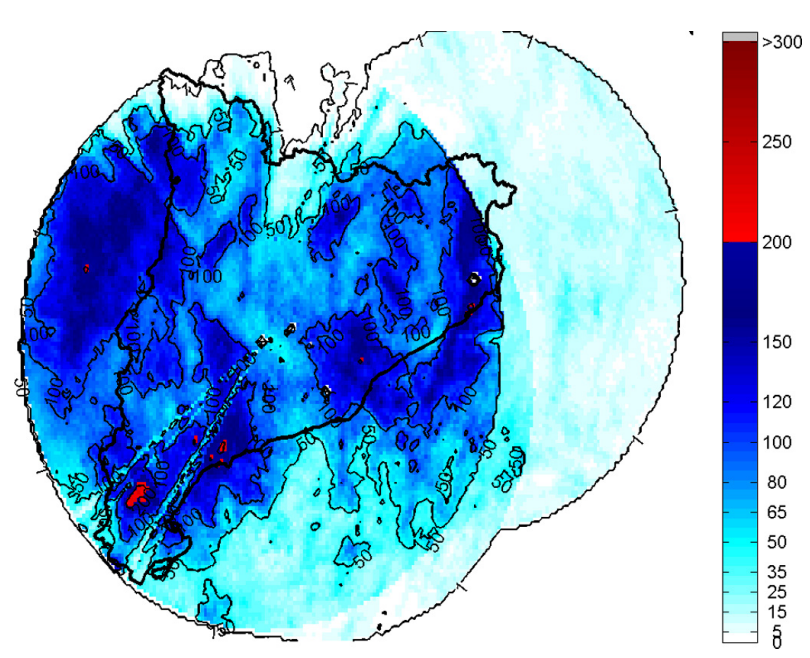

(a) Before advection correction

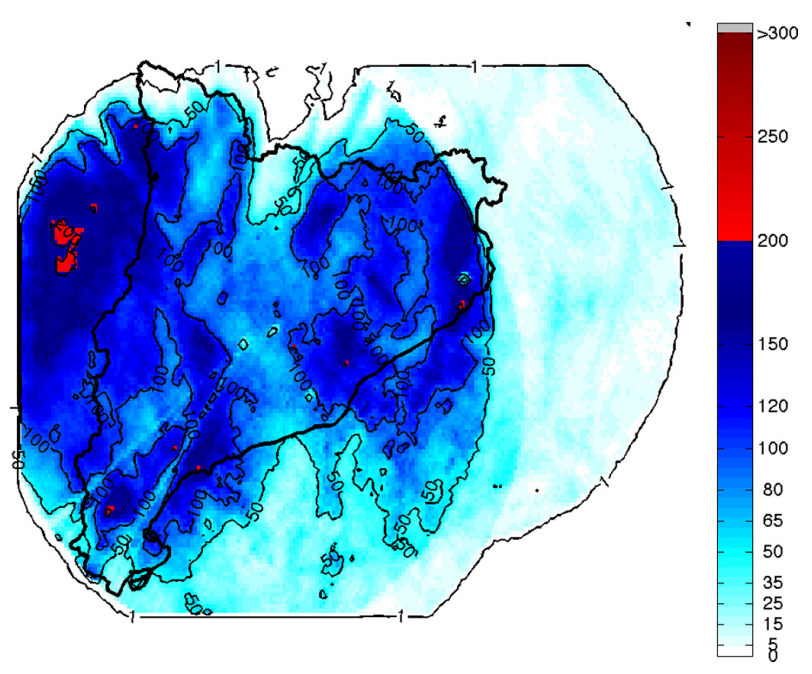

(b) After advection correction

Fig. 11. Comparison between non-advected (a) and advected (b) accumulated rainfall field.

of 12,15 and $18 \mathrm{~min}$. In general, both the width of the confidence intervals and the distances between the median and the observed peak increase as the rainfall time resolution deviates from these values, reaching the maximum at the most extreme time resolutions, i.e. 6 and $30 \mathrm{~min}$. The largest deviations of the median from the observed peak at most stations are also at 6 and $30 \mathrm{~min}$.

The results obtained for the four validation measures are shown in Fig. 14. To allow for the comparison among gauges, RMSE and $\mathrm{ME}_{H}$ were standardised by the observed peak discharge. As shown in Fig. 14a, the minimum RMSE is reached at all stations for $15 \mathrm{~min}$ resolution, except for the Mogoda station. The model performance is maintained for time resolutions below $12 \mathrm{~min}$ but decreases sharply for time resolutions above $18 \mathrm{~min}$ in the case of the smaller stations, Mogoda, Lliça and Garriga. This finding shows that time resolutions coarser than 15 min worsen the hydrological results for the basins with smaller areas.

The absolute value of the bias reaches a minimum for time resolutions of 12 and $15 \mathrm{~min}$, the differences between these two time resolutions being small. The bias shows the same trend as the RMSE for the smaller basins, as it decreases the model performance when time resolution decreases. This finding indicates that time resolutions higher than $15 \mathrm{~min}$ worsen the hydrological results for Mogoda, Lliça and Garriga basins. Although Fig. 14b presents the absolute value of the bias, in general, the bias is positive for time resolutions smaller than $15 \mathrm{~min}$ and negative for the rest. 


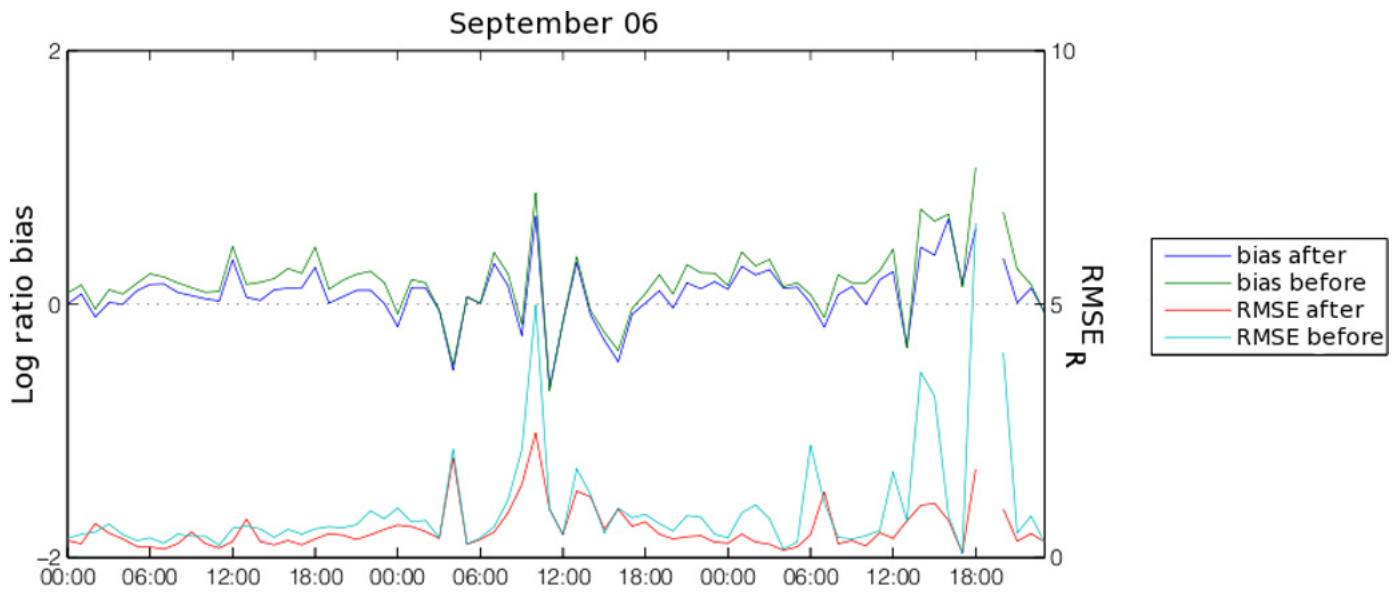

Fig. 12. Validation results for the September 2006 event before and after applying the advection correction.
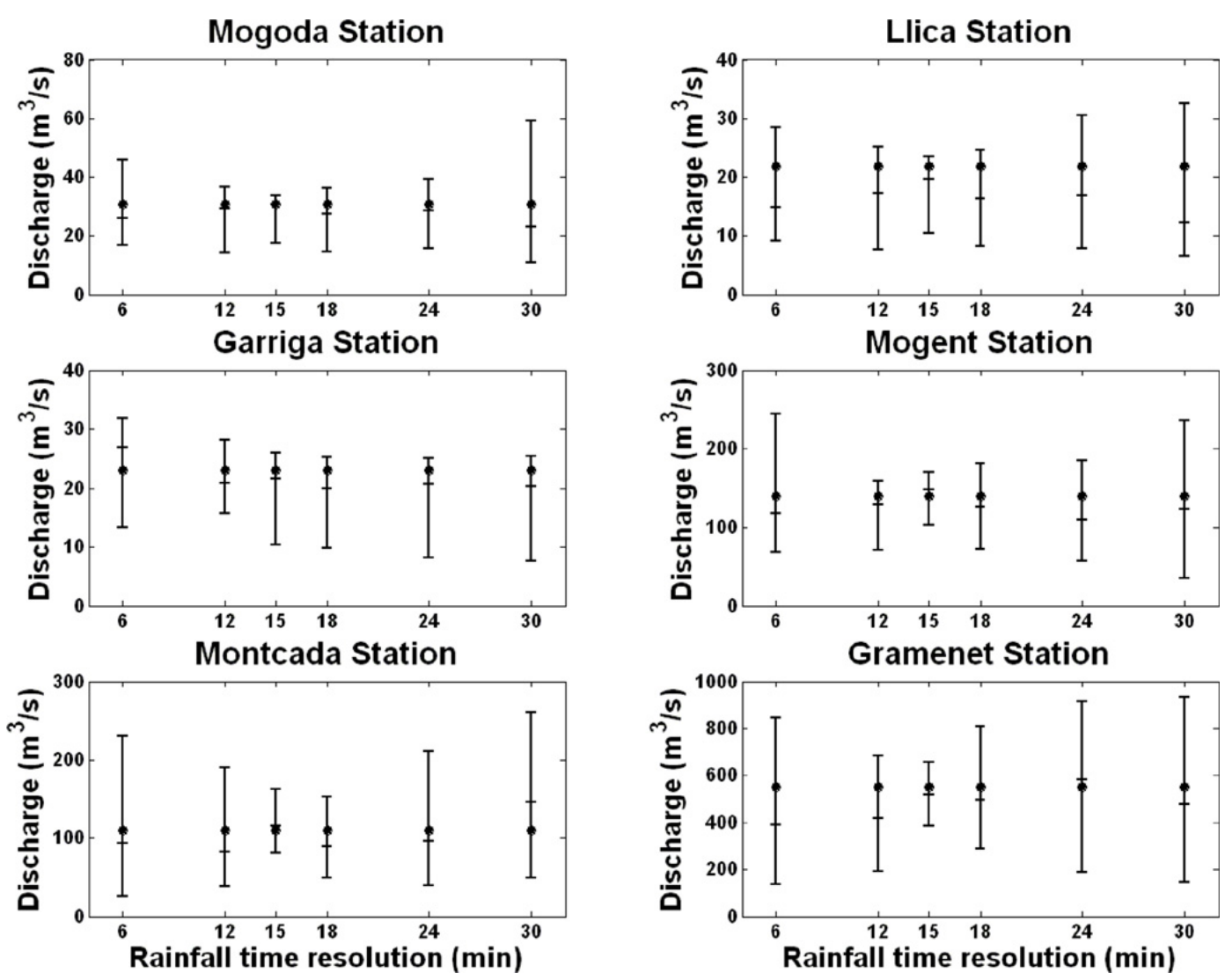

Fig. 13. Validation results for the peak discharge as a function of time resolution, at all station locations. The observed peak discharge is plotted as a solid circle, $5 \%$ and $95 \%$ percentiles are plotted as vertical bars and the median is plotted as a horizontal dash.

Gramenet, Montcada and Mogent Stations clearly reach the best $R^{2}\left(\mathrm{MQ}_{0.5}\right)$ for a time resolution of $15 \mathrm{~min}$. Mogoda and Lliça Stations reach the maximum for $15 \mathrm{~min}$, but there are no large differences from the result for $12 \mathrm{~min}$. Garriga reaches the maximum for $12 \mathrm{~min}$. These results indicate that the larger basins produce better results for a time resolution of $15 \mathrm{~min}$ and that the smaller basins produce better results for a higher time resolution closer to $12 \mathrm{~min}$.

The behaviour of CR shows that most stations reach the maximum for $15 \mathrm{~min}$, except for Lliça, where the maximum corresponds to $12 \mathrm{~min}$. The larger basins (Mogent, Montcada and Gramenet) show a sharp decrease in model performance 
(a)

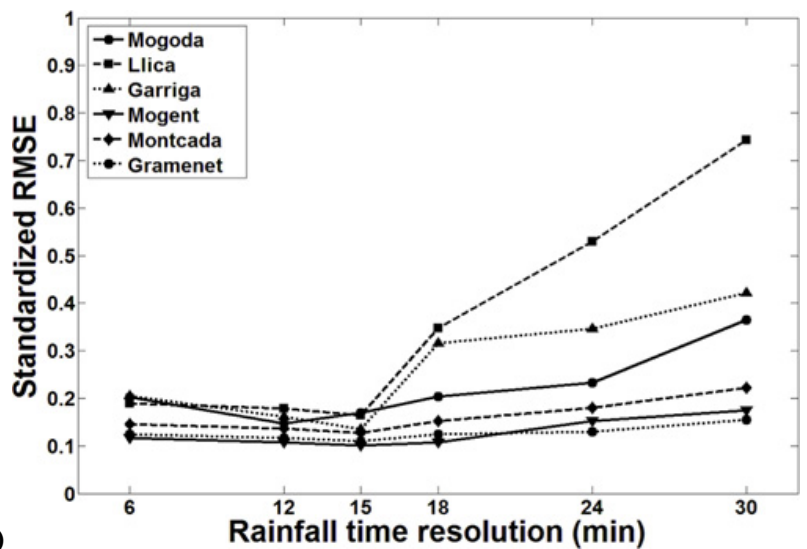

(c)

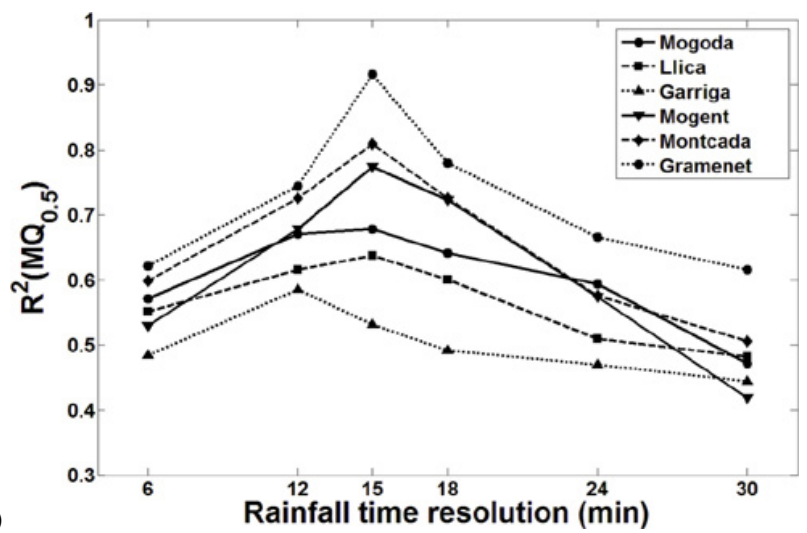

(b)

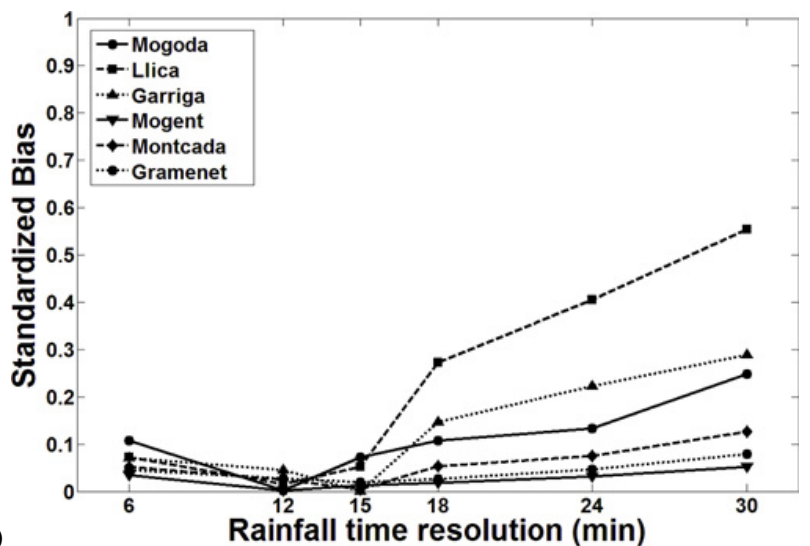

(d)

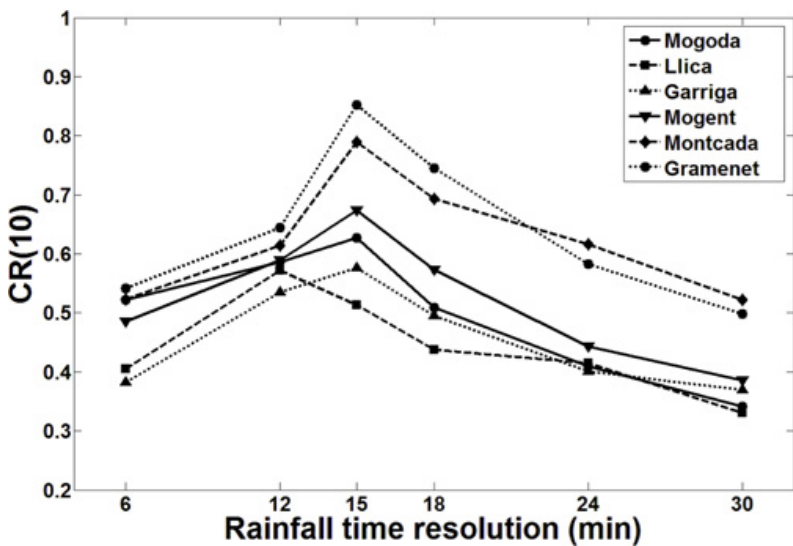

Fig. 14. Validation measures plotted versus rainfall time resolution for all stations. (a) Root Mean Square Error (RMSE), standardized by observed peak discharge (b); absolute value of Bias (ME), standardized by observed peak discharge. (c) ash-Sutcliffe global efficiency index $R^{2}\left(\mathrm{MQ}_{0.5}\right)$. (d) Containing Ratio for a confidence level of $10 \%[\mathrm{CR}(10 \%)]$.

Table 5. Summary of calibration results for each parameter for all time resolutions. Table shows mean value $(\mu)$ and standard deviation $(\sigma)$ of the parameter distribution.

\begin{tabular}{rccccccccc}
\hline & \multicolumn{10}{c}{ Parameter } \\
\cline { 2 - 10 } Time resolution & \multicolumn{1}{c}{$\log _{10}(f)\left[\mathrm{mm}^{-1}\right]$} & \multicolumn{2}{c}{$\alpha[-]$} & \multicolumn{2}{c}{$K_{\mathrm{V}}[-]$} & \multicolumn{2}{c}{$C_{\mathrm{V}}\left[\mathrm{m} \mathrm{h}^{-1}\right]$} \\
$($ min) & $\mu$ & $\sigma$ & $\mu$ & $\sigma$ & $\mu$ & $\sigma$ & $\mu$ & $\sigma$ \\
\hline 6 & -3.05 & 0.92 & 41.6 & 25.8 & 10.1 & 2.82 & 4680 & 1654 \\
12 & -2.15 & 0.71 & 48.6 & 28.9 & 10.9 & 1.80 & 4643 & 1220 \\
15 & -2.63 & 0.68 & 53.4 & 27.1 & 11.3 & 2.15 & 4397 & 1313 \\
18 & -2.30 & 0.51 & 48.9 & 30.6 & 10.7 & 1.75 & 4563 & 1818 \\
24 & -2.32 & 0.29 & 44.0 & 28.8 & 10.1 & 1.95 & 4593 & 1655 \\
30 & -2.65 & 0.69 & 50.6 & 24.4 & 11.1 & 2.77 & 3415 & 1439 \\
\hline
\end{tabular}

as the time resolution increases. The best results are achieved at $15 \mathrm{~min}$ resolution, but the results for $12 \mathrm{~min}$ are worse than those for $18 \mathrm{~min}$. This finding indicates that the results for the larger basins give worse results at time resolutions higher than $15 \mathrm{~min}$. In the case of smaller basins, there are not relevant differences between the results of time resolutions within 12 and $15 \mathrm{~min}$.
It seems that the decrease in model performance with a decrease in time resolution may depend on the maximum time resolution required to characterise the rainfall variability in time. The decrease in model performance for time resolutions higher than $15 \mathrm{~min}$ could be due to the minimum time resolution required for the hydrological model to characterise the runoff processes. This resolution seems to be 
Table 6. Validation results for the selected river gauging stations.

\begin{tabular}{|c|c|c|c|c|c|c|c|}
\hline \multirow[b]{2}{*}{ Gauge station } & \multirow[b]{2}{*}{ Measure } & \multicolumn{6}{|c|}{ Time resolution } \\
\hline & & $30 \mathrm{~min}$ & $24 \mathrm{~min}$ & $18 \mathrm{~min}$ & $15 \mathrm{~min}$ & $12 \mathrm{~min}$ & $6 \min$ \\
\hline \multirow{4}{*}{ Lliça } & RMSE & 16.212 & 11.546 & 7.577 & 3.586 & 3.911 & 4.142 \\
\hline & Bias & -12.072 & -8.843 & -5.939 & -1.143 & 0.325 & 1.568 \\
\hline & $R^{2}\left(\mathrm{MQ}_{0.5}\right)$ & 0.315 & 0.333 & 0.392 & 0.416 & 0.387 & 0.360 \\
\hline & CR $(10 \%)$ & 0.254 & 0.319 & 0.337 & 0.365 & 0.440 & 0.312 \\
\hline \multirow{4}{*}{ Montcada } & RMSE & 24.398 & 19.708 & 16.718 & 13.993 & 14.893 & 16.003 \\
\hline & Bias & -13.842 & -8.157 & -5.891 & 0.548 & 2.744 & 5.747 \\
\hline & $R^{2}\left(\mathrm{MQ}_{0.5}\right)$ & 0.330 & 0.376 & 0.474 & 0.528 & 0.474 & 0.391 \\
\hline & CR $(10 \%)$ & 0.522 & 0.616 & 0.693 & 0.789 & 0.614 & 0.523 \\
\hline \multirow{4}{*}{ Gramenet } & RMSE & 85.530 & 71.237 & 68.725 & 60.656 & 64.435 & 68.516 \\
\hline & Bias & -43.843 & -25.817 & -14.795 & 10.658 & 15.365 & 25.131 \\
\hline & $R^{2}\left(\mathrm{MQ}_{0.5}\right)$ & 0.398 & 0.421 & 0.438 & 0.521 & 0.432 & 0.356 \\
\hline & CR $(10 \%)$ & 0.498 & 0.520 & 0.539 & 0.686 & 0.592 & 0.504 \\
\hline \multirow{4}{*}{ Garriga } & RMSE & 9.726 & 8.003 & 7.278 & 3.108 & 3.736 & 4.741 \\
\hline & Bias & -6.669 & -5.142 & -3.385 & 0.005 & 1.049 & 1.644 \\
\hline & $R^{2}\left(\mathrm{MQ}_{0.5}\right)$ & 0.290 & 0.307 & 0.321 & 0.347 & 0.382 & 0.316 \\
\hline & CR $(10 \%)$ & 0.284 & 0.308 & 0.381 & 0.490 & 0.395 & 0.201 \\
\hline \multirow{4}{*}{ Mogent } & RMSE & 24.586 & 21.422 & 15.130 & 14.257 & 15.020 & 16.460 \\
\hline & Bias & -7.331 & -4.393 & -2.524 & -1.789 & 0.214 & 4.803 \\
\hline & $R^{2}\left(\mathrm{MQ}_{0.5}\right)$ & 0.208 & 0.375 & 0.472 & 0.545 & 0.443 & 0.346 \\
\hline & CR $(10 \%)$ & 0.304 & 0.389 & 0.482 & 0.614 & 0.589 & 0.485 \\
\hline \multirow{4}{*}{ Mogoda } & RMSE & 11.192 & 7.138 & 6.234 & 5.206 & 4.505 & 6.213 \\
\hline & Bias & 7.599 & 4.100 & 3.295 & 2.201 & -0.049 & 3.310 \\
\hline & $R^{2}\left(\mathrm{MQ}_{0.5}\right)$ & 0.243 & 0.388 & 0.419 & 0.443 & 0.438 & 0.373 \\
\hline & CR $(10 \%)$ & 0.284 & 0.341 & 0.424 & 0.543 & 0.468 & 0.435 \\
\hline
\end{tabular}

a threshold for a basin area of $150 \mathrm{~km}^{2}$. Basins with areas below this threshold produce better results with a time resolution of $12 \mathrm{~min}$, causing the model performance to decrease sharply as the time resolution decreases. Basins with areas higher than $150 \mathrm{~km}^{2}$ achieve better results with a time resolution of $15 \mathrm{~min}$.

These results indicate that $15 \mathrm{~min}$ is the best rainfall time resolution for basins larger than $150 \mathrm{~km}^{2}$ in the Besòs Basin and $12 \mathrm{~min}$ is the best resolution for basins smaller than $150 \mathrm{~km}^{2}$. These time resolutions provide a good representation of the rainfall characteristics of the Besòs River basin as well as allow for a good simulation of the hydrological processes that occur in the area.

\section{Discussion}

Distributed hydrological models improve the simulation of convective rainfall events, as they can accept spatially distributed rainfall maps as input data. In this study, an effort was made to couple radar data with a distributed hydrologic model to simulate flash-flood events recorded in Catalonia.
This contribution provides a good example of the numerous problems that exist in QPE. First, the traditional Z/R power-law relationships have not worked well when applied to the selected cases. It is difficult to determine with certainty whether this problem might be associated with poor calibration or maintenance of the radar network, or with the attenuation caused by heavy precipitation. To obtain a suitable QPE, a Window Probability Matching Method (WPMM) and an advection correction were applied in this work.

Despite the dependence of the WPMM on the selected probability distribution fitting function, it has been shown that rainfall estimation improves with the two tested functions. Accordingly, it is interesting that the minimum root mean square error is obtained by fitting parametric functions. Initially, the empirical pdf was tested to reproduce exactly the original WPMM technique. However, the results not only in the lower tail of the distribution, but also in the higher reflectivity tail - show poor stability over the SD test. For this reason, a smooth non-parametric technique (Kernel smooth pdf) was tested. The results improve slightly, but the stability is not sufficiently high. For this reason, several parametric functions were tested.The best-fitting parametric 
functions used were a gamma function for reflectivity and an exponential function for rainfall intensity. Comparing both methodologies, the parametric function provides an increase in lower reflectivity values and a decrease in higher values, whereas the non-parametric methodology produces a similar shape, though it is displaced to the right, which causes the rainfall intensity to increase for all reflectivity values. The second correction made by WPMM non-parametric methodology could be related to the underestimation of the reflectivity due to the power parameter calibration or attenuation due to heavy rainfall.

Taking into account the improvement that involves a convective/stratiform distinction, two $\mathrm{Z} / \mathrm{R}$ relations are obtained. This new QPE method produces better results for the log ratio bias, which indicates a more accurate reproduction of the total rainfall recorded. Furthermore, the new WPMM $\mathrm{Z} / \mathrm{R}$ relation shape is less convex than the previous one. Accordingly, this approach should be useful for obtaining better QPE results if more in-depth rain regime research was performed.

After that, an advection correction was applied to correct the rainfall amount. This correction was based on the hypothesis that rainfall intensities continuously vary in space. This method is applied by several meteorological services to accumulate rainfall over a period of one hour. In the present work, this technique was applied to every six radar rainfall fields with two objectives. The first was to improve the total rainfall estimation; the second was to increase the temporal resolution to feed the hydrological model. By applying this method, the root mean square error decreased, although the bias did not show this behaviour. The cause of this could be the significance of each improvement. The root mean square error is more closely related with point errors, whereas the bias is mainly related to the entire rainfall field.

Comparing the results obtained in the literature for the $\mathrm{Z} / \mathrm{R}$ relations (Atencia et al., 2008) with the results of the combined application of both methodologies, the $\mathrm{RMSE}_{R}$ has been reduced by up to $40 \%$ and $\log$ ratio bias between $75 \%$ and $95 \%$. These accurate results allow us to map the radar rainfall information to the rectangular grid of the DEM by an area-weighted interpolation.

Once a more accurate rainfall field was obtained for each 6-min interval, it was taken as input data for the hydrologic model. Due to the fact that the calibration of distributed hydrological models is strongly dependent on the time resolution of rainfall data, the advection correction method based on a cross-correlation technique was applied to implement a temporal disaggregation at several time resolutions (30, 24, $18,15,12,6$ and $2 \mathrm{~min}$ ). Time resolutions higher than $6 \mathrm{~min}$ lead to both unaffordable computation times for operational hydrological forecasting and irrelevant time resolutions for the gauging stations in the Besòs River Basin. Accordingly, only the six highest time resolutions were compared.

A probabilistic calibration methodology was applied to three flood events to obtain the pdf that best represent the variability of each model parameter. A sensitivity analysis of the rainfall time resolution was performed for the last event. This sensitivity analysis showed that basins with areas below $150 \mathrm{~km}^{2}$ provide better results with a time resolution of $12 \mathrm{~min}$, and basins with areas higher than $150 \mathrm{~km}^{2}$ achieve better results with $15 \mathrm{~min}$ of time resolution. This result may be influenced by the fact that the model was only calibrated for the global outlet at Gramenet. An individual calibration of each of the smaller basins might lead to better overall model performance and would probably yield a lower optimum time resolution in smaller basins. The selected rainfall time resolutions compare well with the results presented by (Berne et al., 2004), who studied urban basins up to $100 \mathrm{~km}^{2}$ and found a strong relationship between basin size and the minimum required rainfall spatial and temporal resolutions, suggesting a rainfall minimum temporal resolution of $12 \mathrm{~min}$.

For the optimum time resolution of $15 \mathrm{~min}$, an RMSE average improvement of $16 \%$ was obtained for all sub-basins analysed when compared to the 6 min time resolution case, which produced values larger than $10 \%$ for all individual basins. The results for other basins could vary across the Mediterranean due to the dependence of the basin response on other characteristics not analysed in this work, such as geomorphology, geology and vegetation.

\section{Conclusions}

The goal of this study was to perform a sensitivity analysis of rainfall time resolution on coupling radar data with a distributed hydrologic model to simulate flash-flood events recorded in Catalonia.

The first step was to obtain a methodology that improves the radar rainfall estimation. The results shows that the application of a WPMM, to compute a new Z/R relation, together with an advection correction, represents a good improvement in radar rainfall estimation.

The advection correction technique was applied to implement a temporal disaggregation at several rainfall time resolutions (from 30 to $6 \mathrm{~min}$ ). After a probabilistic calibration of the hydrological model, a sensitivity analysis of these rainfall time resolutions was performed.

The basins analysed in this work range from 100 to $1000 \mathrm{~km}^{2}$ and present an optimum time resolution between 12 and $15 \mathrm{~min}$. This result proves that the highest available rainfall time resolution does not necessarily provide the best result in terms of the predictability of peak flow when the radar system is coupled with a distributed hydrologic model.

Acknowledgements. This research is supported by the Sixth Framework Programme European Commission FLASH project (no. 036852). It is also included in the framework of the Spanish Severus project (CGL2006-13372-CO2-02). The authors thank Meteocat (Catalan Meteorological Service) for the rainfall data from the XAC and XMET networks and the radar data from the XRAD network. The authors also thank ACA (Catalan Agency 
of Water) for the rainfall and stream flow data from the SAIH network. Additionally, the authors would like to thank CLABSA for the Besòs Basin information.

Edited by: R. Uijlenhoet

\section{References}

Anagnostou, E. and Krajewski, W.: Real-time radar rainfall estimation. Part I: Algorithm formulation, Journal of Atmospheric and Oceanic Technology, 16, 189-197, doi:10.1175/15200426(1999)016<0189:RTRREP> 2.0.CO;2, 1999.

Anquetin, S., Braud, I., Vannier, O., Viallet, P., Boudevillain, B., Creutin, J., and Manus, C.: Sensitivity of the hydrological response to the variability of rainfall fields and soils for the Gard 2002 flash-flood event, J. Hydrol., 394, 134-147, 2010.

Arnaud, P., Bouvier, C., Cisneros, L., and Dominguez, R.: Influence of rainfall spatial variability on flood prediction, J. Hydrol., 260, 216-230, doi:10.1016/S0022-1694(01)00611-4, 2002.

Atencia, A., Ceperuelo, M., Llasat, M., and Vilaclara, E.: A new non power-law Z/R relation in western Mediterranean area for flash-flood events, in: Proceedings of Fifth European Conference on Radar in Meteorology and Hidrology (ERAD)., p. 14, Helsinki, Finland, 7, 2008.

Atlas, D., Rosenfeld, D., Wolff, D., Aeronautics, N., and Space Administration. Goddard Space Flight Center, Greenbelt, M.: Climatologically tuned reflectivity-rain rate relations and links to area-time integrals, J. Appl. Meteorol., 29, 1120-1135, 1990.

Barnolas, M. and Llasat, M. C.: A flood geodatabase and its climatological applications: the case of Catalonia for the last century, Nat. Hazards Earth Syst. Sci., 7, 271-281, doi:10.5194/nhess-7271-2007, 2007.

Barnolas, M., Rigo, T., and Llasat, M. C.: Characteristics of 2-D convective structures in Catalonia (NE Spain): an analysis using radar data and GIS, Hydrol. Earth Syst. Sci., 14, 129-139, doi:10.5194/hess-14-129-2010, 2010.

Bech, J., Codina, B., Lorente, J., and Bebbington, D.: The sensitivity of single polarization weather radar beam blockage correction to variability in the vertical refractivity gradient, J. Atmos. Oceanic Technol., 20, 845-855, doi:10.1175/15200426(2003)020<0845:TSOSPW>2.0.CO;2, 2003.

Bell, V. A. and Moore, R. J.: The sensitivity of catchment runoff models to rainfall data at different spatial scales, Hydrol. Earth Syst. Sci., 4, 653-667, doi:10.5194/hess-4-653-2000, 2000.

Berne, A., Delrieu, G., Creutin, J., and Obled, C.: Temporal and spatial resolution of rainfall measurements required for urban hydrology, J. Hydrology, 299, 166-179, 2004.

Biggerstaff, M. and Listemaa, S.: An improved scheme for convective/stratiform echo classification using radar reflectivity, J. Appl. Meteorol., 39, 2129-2150, doi:10.1175/15200450(2001)040<2129:AISFCS>2.0.CO;2, 2000.

Bouilloud, L., Delrieu, G., Boudevillain, B., and Kirstetter, P.: Radar rainfall estimation in the context of post-event analysis of flash-flood events, J. Hydrol., 394, 17-27, 2010.

Carpenter, T. and Georgakakos, K.: Intercomparison of lumped versus distributed hydrologic model ensemble simulations on operational forecast scales, J. Hydrol., 329, 174-185, doi:10.1016/j.jhydrol.2006.02.013, 2006.
Ceperuelo, M. and Llasat, M.: La Precipitacion Convectiva en las Cuencas Internas de Catalunya, Revista del Aficionado a la Meteorologia, 23, 2004.

Corral, C., Sempere-Torres, D., and Berenguer, M.: A distributed rainfall runoff model to use in Mediterranean basins with radar rainfall estimates, in: 30 Conf. on Radar Meteor, pp. 6-8, 2001.

Delrieu, G., Andrieu, H., and Creutin, J.: Quantification of pathintegrated attenuation for $\mathrm{X}$-and $\mathrm{C}$-band weather radar systems operating in Mediterranean heavy rainfall, J. Appl. Meteorol., 39, 840-850, 2000.

Dransfeld, S., Larnicol, G., and Le Traon, P.: The Potential of the Maximum Cross-Correlation Technique to Estimate Surface Currents From Thermal AVHRR Global Area Coverage Data, IEEE Geoscience and Remote Sensing Letters, 3, 508-511, doi:10.1109/LGRS.2006.878439, 2006.

Fabry, F., Bellon, A., Duncan, M., and Austin, G.: High resolution rainfall measurements by radar for very small basins: the sampling problem reexamined, J. Hydrol., 161, 415-428, 1994.

Franco, M., Sánchez-Diezma, R., and Sempere-Torres, D.: Improving radar precipitation estimates by applying a VPR correction method based on separating precipitation types, in: Proceedings of Fifth European Conference on Radar in Meteorology and Hidrology (ERAD)., p. 14, Helsinki, Finland, 14, 2008.

Freer, J., Beven, K., and Ambroise, B.: Bayesian estimation of uncertainty in runoff prediction and the value of data: An application of the GLUE approach, Water Resour. Res., 32, 2161-2173, 1996.

Garrote, L. and Bras, R.: A distributed model for real-time flood forecasting using digital elevation models, J. Hydrol., 167, 279306, doi:10.1016/0022-1694(94)02592-Y, 1995a.

Garrote, L. and Bras, R.: An integrated software environment for real-time use of a distributed hydrologic model, J. Hydrol., 167, 307-326, 1995b.

Garrote, L., Molina, M., and Mediero, L.: Hydroinformatics in Practice: Computational Intelligence and Technological Developments in Water Applications, chap. Learning Bayesian networks from deterministic rainfall-runoff models and MonteCarlo simulation, pp. 375-388, Springer, doi:10.1007/978-3540-79881-1_27, 2007.

Gupta, H., Sorooshian, S., and Yapo, P.: Toward improved calibration of hydrologic models: Multiple and noncommensurable measures of information, Water Resour. Res., 34, 751-763, 1998.

Haddad, Z., Short, D., Durden, S., Im, E., Hensley, S., Grable, M., and Black, R.: A new parametrization of the rain drop size distribution, IEEE Transactions on Geoscience and Remote Sensing, 35, 532-539, doi:10.1109/36.581961, 1997.

Hazenberg, P., Yu, N., Boudevillain, B., Delrieu, G., and Uijlenhoet, R.: Scaling of raindrop size distributions and classification of radar reflectivity-rain rate relations in intense Mediterranean precipitation, J. Hydrol., 402, 179-192, 2011.

Kaplan, E. and Meier, P.: Nonparametric estimation from incomplete observations, J. Am. Statistical Association, 53, 457-481, doi:10.2307/2281868, 1958.

Krajewski, W., Lakshmi, V., Georgakakos, K., and Jain, S.: A Monte Carlo study of rainfall sampling effect on a distributed catchment model, Water Resour. Res., 27, 119-128, doi:10.1029/90WR01977, 1991.

Lee, G. and Zawadzki, I.: Variability of drop size distributions: Time-scale dependence of the variability and its ef- 
fects on rain estimation, J. Appl. Meteorol., 44, 241-255, doi:10.1175/JAM2183.1, 2005.

Liu, C. and Krajewski, W.: A comparison of methods for calculation of radar-rainfall hourly accumulations, J. Am. Water Resour. Assoc., 32, 305-315, doi:10.1111/j.1752-1688.1996.tb03453.x, 1996.

Llasat, M., Rigo, T., and Barriendos, M.: The Montserrat-2000 flash-flood event: a comparison with the floods that have occurred in the northeastern Iberian Peninsula since the 14th century, Int. J. Climatol., 23, 453-469, doi:10.1002/joc.888, 2003.

Llasat, M. C., López, L., Barnolas, M., and Llasat-Botija, M.: Flash-floods in Catalonia: the social perception in a context of changing vulnerability, Adv. Geosci., 17, 63-70, doi:10.5194/adgeo-17-63-2008, 2008.

Madsen, H.: Parameter estimation in distributed hydrological catchment modelling using automatic calibration with multiple objectives, Adv. Water Resour., 26, 205-216, doi:10.1016/S03091708(02)00092-1, 2003.

Marchi, L., Borga, M., Preciso, E., and Gaume, E.: Characterisation of selected extreme flash floods in Europe and implications for flood risk management, J. Hydrol., 394, 118-133, 2010.

Marshall, J. and Palmer, W.: The distribution of raindrops with size, J. Atmos. Sci., 5, 165-166, doi:10.1175/15200469(1948)005<0165:TDORWS > 2.0.CO;2, 1948.

Mediero, L., Garrote, L., and Martin-Carrasco, F.: A probabilistic model to support reservoir operation decisions during flash floods/Un modele probabiliste d'aide a la decision pour la gestion d'un reservoir lors de crues eclairs, Hydrol. Sci. J., 52, 523537, doi:10.1623/hysj.52.3.523, 2007.

Mediero, L., Garrote, L., and Martín-Carrasco, F.: Probabilistic calibration of a distributed hydrological model for flood forecasting, Hydrol. Sci. J., 56, 1129-1149, 2011.

Montanari, A.: Large sample behaviors of the generalized likelihood uncertainty estimation (GLUE) in assessing the uncertainty of rainfall-runoff simulations, Water Resour. Res., 41, W08406, doi:10.1029/2004WR003826, 2005.

Morin, E. and Gabella, M.: Radar-based quantitative precipitation estimation over Mediterranean and dry climate regimes, J. Geophys. Res.-Atmospheres, 112, D20108, doi:10.1029/2006JD008206, 2007.

Morin, E., Enzel, Y., Shamir, U., and Garti, R.: The characteristic time scale for basin hydrological response using radar data, J. Hydrol., 252, 85-99, doi:10.1016/S0022-1694(01)00451-6, 2001.

Nicótina, L., Alessi Celegon, E., Rinaldo, A., and Marani, M.: On the impact of rainfall patterns on the hydrologic response, Water Resour. Res., 44, W12401, doi:10.1029/2007WR006654, 2008.

Parzen, E.: On estimation of a probability density function and mode, The Annals of Mathematical Statistics, 33, 1065-1076, doi:10.1214/aoms/1177704472, 1962.

Price, C., Yair, Y., Mugnai, A., Lagouvardos, K., Llasat, M. C., Michaelides, S., Dayan, U., Dietrich, S., Galanti, E., Garrote, L., Harats, N., Katsanos, D., Kohn, M., Kotroni, V., Llasat-Botija, M., Lynn, B., Mediero, L., Morin, E., Nicolaides, K., Rozalis, S., Savvidou, K., and Ziv, B.: The FLASH Project: using lightning data to better understand and predict flash floods, Environmental Science Policy, 14, 898-911,doi:10.1016/j.envsci.2011.03.004, 2011.

Refsgaard, J.: Parameterisation, calibration and validation of distributed hydrological models, J. Hydrol., 198, 69-97, doi:10.1016/S0022-1694(96)03329-X, 1997.

Rigo, T.: Estudio de sistemas convectivos mesoescalares en la zona mediterránea occidental mediante el uso del radar meteorológico, $\mathrm{Ph} . \mathrm{D}$. thesis, $\mathrm{PhD}$ thesis, University of Barcelona, Internal publication, 2004.

Rigo, T. and Llasat, M. C.: A methodology for the classification of convective structures using meteorological radar: Application to heavy rainfall events on the Mediterranean coast of the Iberian Peninsula, Nat. Hazards Earth Syst. Sci., 4, 59-68, doi:10.5194/nhess-4-59-2004, 2004.

Rinehart, R. and Garvey, E.: Three-dimensional storm motion detection by convective weather radar, Nature, 273, 287-289, 1978.

Robinson, J., Sivapalan, M., and Snell, J.: On the relative roles of hillslope processes, channel routing, and network geomorphology in the hydrologic response of natural catchments, Water Resour. Res., 31, 3089-3101, doi:10.1029/95WR01948, 1996.

Rosenfeld, D., Wolff, D., and Atlas, D.: General probabilitymatched relations between radar reflectivity and rain rate, J. Appl. Meteorol., 32, 50-72, doi:10.1175/15200450(1993)032<0050:GPMRBR > 2.0.CO;2, 1993.

Rosenfeld, D., Wolff, D., and Amitai, E.: The window probability matching method for rainfall measurements with radar, J. Appl. Meteorol., 33, 682-693, doi:10.1175/15200450(1994)033<0682:TWPMMF>2.0.CO;2, 1994.

Rosenfeld, D., Amitai, E., and Wolff, D.: Improved accuracy of radar WPMM estimated rainfall upon application of objective classification criteria, J. Appl. Meteorol., 34, 212-223, doi:10.1175/1520-0450-34.1.212, 1995.

Sánchez-Diezma, R., Zawadzki, I., and Sempere-Torres, D.: Identification of the bright band through the analysis of volumetric radar data, J. Geophys. Res.-Atmos., 105, 2225-2236, doi:10.1029/1999JD900310, 2000.

Sánchez-Diezma, R., Sempere-Torres, D., Delrieu, G., and Zawadzki, I.: An improved methodology for ground clutter substitution based on a pre-classification of precipitation types, in: 30 th Internat. Conf. on Radar Meteor, pp. 271-273, Munich, Germany, 2001.

Sangati, M., Borga, M., Rabuffetti, D., and Bechini, R.: Influence of rainfall and soil properties spatial aggregation on extreme flash flood response modelling: an evaluation based on the Sesia river basin, North Western Italy, Adv. Water Resour., 32, 1090-1106, 2009.

Smith, M., Seo, D., Koren, V., Reed, S., Zhang, Z., Duan, Q., Moreda, F., and Cong, S.: The distributed model intercomparison project (DMIP): motivation and experiment design, J. Hydrol., 298, 4-26, doi:10.1016/j.jhydrol.2004.03.040, 2004.

Steinacker, R., Dorninger, M., Wölfelmaier, F., and Krennert, T.: Automatic tracking of convective cells and cell complexes from lightning and radar data, Meteorol. Atmos. Phys., 72, 101-110, doi:10.1007/s007030050009, 2000.

Steiner, M., Houze Jr, R., and Yuter, S.: Climatological characterization of three-dimensional storm structure from operational radar and rain gauge data, J. Appl. Meteorol., 34, 1978-2007, doi:10.1175/1520-0450(1995)034<1978:CCOTDS > 2.0.CO;2, 1995.

Turk, G. and O'Brien, J. F.: Shape transformation using variational implicit functions, in: SIGGRAPH '05: ACM SIGGRAPH 2005 Courses, p. 13, ACM, New York, NY, USA, 
doi:10.1145/1198555.1198639, 2005.

Velasco-Forero, C., Sempere-Torres, D., Sanchez-Diezma, R., Cassiraga, E., and Gomez-Hernandez, J.: A non-parametric methodology to merge raingauges and radar by kriging: sensitivity to errors in radar measurements, in: Proceedings of Third European Conference on Radar in Meteorology and Hidrology (ERAD)., pp. 21-24, Visby, Island of Gotland, Sweden, 2004.

Winchell, M., Gupta, H., and Sorooshian, S.: On the simulation of infiltration-and saturation-excess runoff using radarbased rainfall estimates: Effects of algorithm uncertainty and pixel aggregation, Water Resour. Res., 34, 2655-2670, doi:10.1029/98WR02009, 1998.
Xiong, L. and O'Connor, K.: An empirical method to improve the prediction limits of the GLUE methodology in rainfall-runoff modeling, J. Hydrol., 349, 115-124, 2008.

Yang, D., Herath, S., and Musiake, K.: Comparison of different distributed hydrological models for characterization of catchment spatial variability, Hydrol. Process, 14, 403416, doi:10.1002/(SICI)1099-1085(20000228)14:3<403::AIDHYP945>3.0.CO;2-3, 2000.

Yapo, P., Gupta, H., and Sorooshian, S.: Multi-objective global optimization for hydrologic models, J. Hydrol., 204, 83-97, 1998.

Zawadzki, I.: On radar-raingage comparison, J. Appl. Meteorol., 14, 1430-1436, doi:10.1175/15200450(1975)014<1430:ORRC>2.0.CO;2, 1975. 